\title{
Neuroanatomical and Neurochemical Substrates of Timing
}

\author{
Jennifer T Coull ${ }^{\star, 1}$, Ruey-Kuang Cheng ${ }^{2}$ and Warren H Meck $^{2}$ \\ ${ }^{1}$ Laboratoire de Neurobiologie de la Cognition, Pole 3C, Université de Provence and CNRS, Marseille, France; \\ ${ }^{2}$ Department of Psychology and Neuroscience, Duke University, Durham, NC, USA
}

\begin{abstract}
We all have a sense of time. Yet, there are no sensory receptors specifically dedicated for perceiving time. It is an almost uniquely intangible sensation: we cannot see time in the way that we see color, shape, or even location. So how is time represented in the brain? We explore the neural substrates of metrical representations of time such as duration estimation (explicit timing) or temporal expectation (implicit timing). Basal ganglia (BG), supplementary motor area, cerebellum, and prefrontal cortex have all been linked to the explicit estimation of duration. However, each region may have a functionally discrete role and will be differentially implicated depending upon task context. Among these, the dorsal striatum of the BG and, more specifically, its ascending nigrostriatal dopaminergic pathway seems to be the most crucial of these regions, as shown by converging functional neuroimaging, neuropsychological, and psychopharmacological investigations in humans, as well as lesion and pharmacological studies in animals. Moreover, neuronal firing rates in both striatal and interconnected frontal areas vary as a function of duration, suggesting a neurophysiological mechanism for the representation of time in the brain, with the excitatory-inhibitory balance of interactions among distinct subtypes of striatal neuron serving to fine-tune temporal accuracy and precision.

Neuropsychopharmacology Reviews (2011) 36, 3-25; doi: I 0. I038/npp.20 I0.1 I3; published online 28 July 2010
\end{abstract}

Keywords: putamen; dopamine; glutamate; Parkinson's Disease; temporal prediction; hazard function

\section{INTRODUCTION}

\section{Timing: Some Definitions and Clarifications}

'Everyone knows what attention is,' famously stated William James in his Principles of Psychology (1890). But just as attention is a multifaceted process (selective, divided, and sustained), so too is timing. Laypeople and scientists alike commonly use the term 'timing' to refer not only to how long an event lasts (estimation of duration), but also when an event is likely to occur (prediction of event onset or offset) or even whether it occurred before or after some temporal landmark (temporal order judgment). Both duration estimation and temporal prediction require a metrical representation of time, in which the timing (duration or onset) of a single event can be measured on a continuous, parametric timescale. On the other hand, temporal order judgments require an ordinal representation of time, in which the relative timing of at least two events

${ }^{*}$ Correspondence: $\operatorname{Dr}$ JT Coull, Laboratoire de Neurobiologie de la Cognition, Université de Provence and CNRS, Université de Provence, Pole 3C, 3 Place Victor Hugo, Marseille 13001, France, Tel: + 33413550 942, Fax: + 33488576872 ,

E-mail: jennifer.coull@univ-provence.fr

Received 8 March 2010; revised 29 June 2010; accepted 29 June 2010 are compared with one another in a much more categorical manner. We restrict our review to the study of metrical timing. For discussion of the ordinal characteristics of timing, we direct readers to reviews of temporal order judgments made in the timeframe of a few tens of milliseconds (Battelli et al, 2007), a few seconds (Marshuetz and Smith, 2006), or even a few days, in which case temporal order memory processes come into play (Friedman, 1993; St Jacques et al, 2008). We further restrict our review to investigations of metrical timing in the milliseconds to seconds range, otherwise known as 'interval timing', which has been conserved across a wide range of species (Buhusi and Meck, 2005; Gibbon et al, 1997; Lejeune and Wearden, 2006; Penney et al, 2008; Wearden and Lejeune, 2008).

\section{Duration Estimation or 'Explicit Timing'}

In this review, we concentrate largely on studies of duration estimation, otherwise known as 'explicit timing' (Coull and Nobre, 2008). Explicit timing demands an overt estimate of stimulus duration or interstimulus interval (ISI), either in the form of a perceptual discrimination ('perceptual timing'), in which subjects typically state whether one stimulus duration or ISI is shorter or longer than another, or in the form of a motor response ('motor timing'), in 
which subjects represent the timed duration or ISI with a sustained, delayed, or periodic motor act. For example, the task most commonly used to examine motor timing is the paced finger tapping task, in which subjects first synchronize motor responses to sensory stimuli presented at regular temporal intervals and then, during the subsequent 'continuation' phase, they reproduce motor representations of the learned interval in the absence of the sensory pacing stimulus.

These tasks describe how the estimated interval or duration can be registered. But how does the duration get estimated in the first place? And how do we represent that duration in the brain? The most widely cited model of duration estimation is the pacemaker-accumulator model (Gibbon et al, 1984; Treisman, 1963). In this model, a sensory signal (eg, the onset of a stimulus to be timed) triggers an accumulator to begin counting pulses that are emitted by an internal pacemaker. The accumulated pulse tally can then be passed into working memory for comparison with a previously stored pulse tally. Depending on whether or not these two tallies match, the appropriate response can be given. For example, in a motor timing task the subject would withhold responding until a match was achieved, whereas in a perceptual timing task the subject could monitor whether the currently accumulating tally attained, or extended beyond, the stored tally. The addition of an attentional gate (Zakay and Block, 1996) or switch (Lejeune, 1998) to the model accounts for the well-known phenomenon of 'time flies when you're having fun' and, conversely, 'a watched pot never boils.' In brief, the less attention is paid to the passing of time (because it is otherwise engaged in a more absorbing activity), the fewer pulses are accounted for by the accumulator, leading to an overall underestimation of duration (Buhusi and Meck, 2009a). Changes in aging, emotional arousal, and brain norepinephrine systems have been shown to modulate these attentional processes involved in timing and time perception (Droit-Volet and Meck, 2007; Lustig, 2003; Lustig and Meck, 2001; Meck and MacDonald, 2007; Penney et al, 1996).

Although this psychological model holds intuitive appeal, and has been widely validated by behavioral studies in both animals and humans, it has come under recent attack (Bhattacharjee, 2006) from neurophysiologists seeking a more neurally plausible alternative. Specifically, many neuroscientists now advocate that time is not represented in a centralized, supramodal timer but, rather, is an emergent property of the pattern of neural firing in functionally distributed specialized areas: timing of an auditory stimulus would be indexed by changes in the neural dynamics of auditory cortex whereas timing a visual stimulus would be represented by changes in neural firing patterns in visual cortex. There are several possibilities for the way in which neural firing has been proposed to code for time, for example, the temporal integration of steadily climbing activity throughout the duration (Akkal et al, 2004; Lewis and Miall, 2006; Reutimann et al, 2004) or the detection of spatially distinct, duration-specific patterns of firing (Karmarkar and Buonomano, 2007; Matell and Meck, 2004). Yet, although there is ample evidence for modalityspecific representations of time, these studies almost exclusively examine durations in the tens to hundreds of milliseconds range (Bueti et al, 2008a; Johnston et al, 2006; Karmarkar and Buonomano, 2007; Morrone et al, 2005). For longer durations, necessitating attentional and mnemonic resources, a dedicated internal timer, incorporating many of the elements of the pacemaker-accumulator model (eg, storage and comparison in working memory, attentional gate, and decision processes), may well be needed (see also Buhusi and Meck, 2009a, b; Ivry and Schlerf, 2008; Matell and Meck, 2000).

\section{Temporal Prediction or 'Implicit Timing'}

In this review, we also mention some key investigations of temporal prediction, a subset of 'implicit timing' studies (Coull and Nobre, 2008). Implicit timing is recruited when the regular temporal pattern of sensory stimuli or motor responses can be used to achieve non-temporal task goals. For example, the velocity parameters of an oncoming vehicle can be used to estimate when it would be likely to reach us (time to contact (TTC), Lee, 1976) to determine whether we can safely cross the road. Here, temporal predictions are used to achieve a non-temporal goal (safely crossing the road) rather than being used to provide overt estimates of elapsing time (eg, comparing whether TTC for this car is shorter or longer than TTC of the previous passing car). In this example, temporal predictability is induced incidentally by the rhythmic or constant temporal dynamics of the stimuli themselves ('exogenous' cues). However, temporal predictability can also be induced voluntarily by informative warning cues ('endogenous' cues). For example, predicting when an amber traffic light will turn red accesses ingrained associations between sensory cues and event timing, allowing temporal predictions to be made and driving behavior to be adjusted accordingly. But whether predictions are established incidentally or voluntarily, experimental data have shown that temporal predictability improves both accuracy (Barnes and Jones, 2000; Correa et al, 2005) and speed (Coull and Nobre, 1998; Niemi and Näätänen, 1981; Praamstra et al, 2006) of non-temporal task goals.

Yet, temporally predictive sensory cues are not the only effective strategy for predicting event timing. To continue with our traffic analogies, imagine waiting for a late-running bus. The longer you stand at the bus stop, the more you expect the bus to appear some time soon. This ever-heightening temporal expectation illustrates the experimental phenomenon of the 'hazard function' - the increasing conditional probability over time that an event will occur given that it has not already occurred (Elithorn and Lawrence, 1955; Luce, 1986). The objectively increasing conditional probability (and, hence, the subjectively increasing sense of temporal expectation) over time relies 
on the predictive power of the unidirectional flow of time, or 'time's arrow' (Eddington, 1928). Because time flows inexorably forward, an event that we expect to occur, but has not yet occurred, it must do so at some time in the future. In this case, temporal predictions are driven not by sensory cues but by the very passing of time itself.

\section{NEUROANATOMICAL SUBSTRATES OF TIMING}

\section{Lesion and TMS Studies in Humans: Identifying Critical Timing Regions}

Cerebellum and prefrontal cortex. There are no neurological disorders characterized by temporal deficits, in the way that hemineglect is characterized by spatial deficits, or Parkinson's disease (PD) is characterized by motor deficits. However, focal lesions in several key brain structures have repeatedly been shown to result in timing dysfunction. One of the earliest and most influential reports (Ivry and Keele, 1989) compared the performance of patients with PD to those with cerebellar or cortical lesions. Patients with cerebellar lesions were the only patient group to show both increased motor timing variability and impairments in the accuracy of perceptual timing, suggesting a supramodal role for the cerebellum in timing. Since this initial report, the deleterious effects of cerebellar lesions on motor timing seem robust (Gooch et al, 2010; Harrington et al, 2004b; Ivry and Keele, 1989; Malapani et al, 1998a; Spencer et al, 2003). However, the effects of cerebellar lesions on perceptual timing are more mixed, with the reported deficits being either marginal (Harrington et al, 2004b; see also Ivry and Spencer, 2004), nonselective (Casini and Ivry, 1999), or restricted to specific duration ranges (Nichelli et al, 1996). However, by contrast to patients with prefrontal lesions, whose timing deficits are exacerbated by increasing attentional (Casini and Ivry, 1999) or working memory (Mangels et al, 1998) load, the perceptual timing deficit in cerebellar patients is unaffected by attentional or mnemonic manipulation (although see Nichelli et al, 1996). This is most likely because of the fact that cerebellar timing deficits, whether perceptual (Ivry and Keele, 1989; Casini and Ivry, 1999; Mangels et al, 1998) or motor (Ivry and Keele, 1989; Spencer et al, 2003; Harrington et al, 2004b), have been shown for short, generally sub-second durations only, which of course require minimal attentional or mnemonic processing. These neuropsychological observations have been confirmed by recent transcranial magnetic stimulation (TMS) evidence: TMS of the cerebellum impairs timing of sub-, not supra-second, durations (Fierro et al, 2007; Koch et al, 2007; Lee et al, 2007) whereas TMS of right prefrontal cortex impairs timing of supra-, not sub-second, durations (Jones et al, 2004; Koch et al, 2007). Neuropsychological studies of patients with lesions to right prefrontal cortex similarly show timing deficits that are restricted to longer durations (eg, Danckert et al, 2007; Kagerer et al, 2002; Koch et al, 2002); yet, without the inclusion of control tasks it is difficult to conclude that these deficits reflect a real timing problem. Instead, they could simply reflect the increased sustained attention or working memory demands required by timing long durations, both of which are processes known to engage right prefrontal cortex (Coull et al, 1998; Owen et al, 1999).

Functional specialization for sub-second timing within a discrete zone of the cerebellum has been suggested by studies showing that deficits are found selectively in patients whose lesions extend into the more superior parts of the cerebellum (Harrington et al, 2004b; Gooch et al, 2010). Such anatomical localization has been refined yet further by studies showing that motor timing deficits seem to be caused particularly by lesions to lateral, not medial, regions of the cerebellum (Ivry et al, 1988; Malapani et al, 1998a). Moreover, TMS studies in healthy volunteers suggest a putative functional specialization of lateral $v s$ medial regions of the cerebellum for auditory $v s$ visual representations of time (Del Olmo et al, 2007). TMS to medial, but not lateral, cerebellum increased timing variability for visual timing (Theoret et al, 2001), whereas TMS of lateral cerebellum impaired auditory (Del Olmo et al, 2007) but not visual (Jäncke et al, 2000) timing.

Spencer et al (2003) found deleterious effects of cerebellar lesions on motor timing when patients were required to form an explicit representation of time (up to $1 \mathrm{~s}$ ) but not for a more implicit form of timing (continuous circle drawing) in which temporal regularities were manifest as an emergent property of the motor act itself. However, Bo et al (2008) have recently failed to replicate the results of Spencer et al (2003), instead finding impairments on both explicit and implicit measures of motor timing. Furthermore, cerebellar patients have also been reported to show deficits on implicit measures of perceptual timing, in which patients are required to use the temporal information inherent in the velocity of a moving object to predict its spatio-temporal trajectory (Bares et al, 2007; Beudel et al, 2008). (The cerebellum is also activated by functional neuroimaging studies of spatio-temporal prediction; O'Reilly et al, 2008; Beudel et al, 2009.) In these tasks, fixed temporal contingencies (ie, the constant velocity of the moving object) allow predictions about the time of onset of a sensory target event to be made. In addition, TMS to the cerebellum impairs performance during the synchronization phase of the paced finger tapping task (Del Olmo et al, 2007), in which the regular temporal structure of sensory input allows temporal predictions to be made. Therefore, there seems to be a dissociation in the cerebellum's role in motor $v s$ perceptual forms of implicit timing. It seems not to be needed when regular temporal structure is an emergent property of a motor act (Spencer et al, 2003) but is engaged when the regular temporal structure of perceptual input allows predictions about the onset of upcoming sensory events to be made. This predictive function is, of course, consistent with the feed-forward mechanisms thought to be instantiated in the cerebellum (Wolpert et al, 1998), which allow predictions about the consequences of motor acts 
to be made, thus short-circuiting the need for sensory feedback.

However, regular or rhythmic temporal structure is not the only way of formulating temporal predictions. They can also be based upon the predictive nature of the flow of time itself. If a target does not appear when expected, the likelihood that it will appear in the next moment increases with passing time (hazard function). Increasing likelihood induces increased response preparation, resulting in faster reaction times (RTs) when the target eventually appears (Niemi and Nääänen, 1981). The 'variable foreperiod' paradigm measures the behavioral manifestation of the hazard function: when short and long cue-target foreperiods are mixed within a block of trials, RTs are monotonically faster for targets appearing after long rather than short foreperiods because of the increasing conditional probability of target appearance over time. Patients with lesions to the right prefrontal cortex fail to show the RT benefit of long foreperiods that is shown by normal volunteers, or even by patients with lesions to left or medial areas of prefrontal cortex (Stuss et al, 2005; Trivino et al, 2010; Vallesi et al, 2007a). TMS to right, but not left, prefrontal cortex in healthy volunteers confirmed this finding (Vallesi et al, 2007b). Vallesi et al (2007b, 2009) have suggested that this effect reflects the monitoring role of the right prefrontal cortex: as the foreperiod unfolds, prefrontal cortex uses sensory feedback to constantly update temporal expectations, depending on whether or not the target has yet been presented. The feedback role of the prefrontal cortex in updating temporal predictions contrasts neatly with the more feed-forward role of the cerebellum in establishing temporal predictions in the first place.

Basal ganglia. PD results from degeneration of dopamine (DA)-producing neurons in the substantia nigra (SN) that project to the dorsal striatum (caudate and putamen) of the basal ganglia (BG). PD can therefore be used as a model of BG dysfunction. In contrast to the effects of cerebellar lesions, PD patients show no difficulties in using temporal information to predict the trajectory of a moving object (Bares et al, 2010; Beudel et al, 2008). They also show the normal RT benefits for temporally predictable targets in simple (Jahanshahi et al, 1992, 1993) and choice (Praamstra and Pope, 2007) RT tasks. These findings therefore suggest that BG are less important than the cerebellum in making fixed temporal predictions, that is, in implicit perceptual timing. This conclusion is supported by therapeutic evidence that PD patients can make use of rhythmic sensory timing cues (eg, an auditory metronome or regularly spaced visual markers on the floor) to improve the motor symptoms of their disease (Lim et al, 2005; Thaut et al, 1996). If BG were critical for implicit timing, PD patients would not be able to make use of these sensory cues. In support of this, deep brain stimulation of the BG has little effect on sensory cued timing, although it does help internally generated timing (Schenk et al, 2003). Finally, another measure of implicit timing, 'temporal binding', which measures the temporal window within which sensory events are perceived as being caused by previous voluntary actions, is no different in PD patients and controls (Moore et al, 2010). (Note, however, that although the disease itself had no effect on temporal binding, dopaminergic medication effectively 'pulled' the perceived time of onset of patients' actions and subsequent sensory events toward one another, thus increasing a sense of their causal association.)

Data on the role of BG in using the passage of time to predict stimulus onset (ie, the hazard function) are less clear for the moment. One study reports an impaired ability to benefit from long foreperiods in PD patients (Jurkowski et al, 2005), whereas another shows the normal benefits of long foreperiods in patients with BG lesions (Trivino et al, 2010). Because the behavioral implementation of the hazard function seems to rely upon right prefrontal cortex (Stuss et al, 2005; Vallesi et al, 2007a, b), the discrepancy in these findings could potentially be explained by a discrepancy in the relative integrity of fronto-striatal loops in PD patients compared to those with focal BG lesions.

The overall lack of impairment on implicit forms of perceptual timing in PD can be contrasted to reports that patients show deficits on more explicit forms of timing. Although PD is a disease primarily characterized by motor dysfunction, timing deficits have been observed not only for tasks of motor timing but also for those of perceptual timing in which the patients' primary motor disorder should have minimal effect. For example, PD patients temporarily withdrawn from dopaminergic medication showed impaired temporal discrimination for tactile, auditory, or visual stimuli when compared with controls (Artieda et al, 1992), with the size of the impairment being correlated with disease severity. Even when patients are tested in a medicated state, there is evidence for impaired temporal discrimination in both the sub-second (Harrington et al, 1998) and seconds (Smith et al, 2007) time range. However, a more recent study (Wearden et al, 2008) using a battery of perceptual timing tasks, testing patients both off and on medication, failed to find any evidence of timing dysfunction. The researchers suggested that one possible explanation for the lack of impairment was the relatively early stage of the disease of their patient sample. Such a conclusion is supported by the findings of Artieda et al (1992) that timing deficits are correlated with disease severity.

Paradoxically, for a disease characterized by motor dysfunction, tests of motor timing have produced more mixed results. Timing performance during the continuation phase of the paced finger tapping task in patients with PD or BG lesions has been reported to be either more variable than controls (Freeman et al, 1993; Harrington et al, 1998; O’Boyle et al, 1996) or, conversely, unimpaired (Aparicio et al, 2005; Ivry and Keele, 1989; Spencer and Ivry, 2005). Recently, Merchant et al (2008) have attempted to inject some clarity into the findings using cluster analysis to show that across a range of perceptual and motor timing tasks, 
PD patients fall into two distinct subgroups: those showing high temporal variability and those performing no differently than controls. These two subgroups did not differ in terms of disease duration, severity of clinical symptoms, or age, suggesting that this division reflects a real heterogeneity in timing ability. Such underlying heterogeneity in the temporal performance of the patient sample (which, incidentally, was also noted for control subjects although the temporally variable control group was significantly less variable than the temporally impaired PD group) is clearly a contributing factor in determining whether significant increases in PD timing variability can be observed.

In contrast, one of the most reliable effects in studies of motor timing in PD is the so-called 'migration effect.' Using a temporal reproduction task, Malapani et al (1998b) found that PD patients who were off medication overestimated a pre-learned short duration $(8 s)$ at the same time as underestimating a long one $(21 \mathrm{~s})$, such that duration estimates tended to 'migrate' toward a common, central value (see also Koch et al, 2004, 2005). However, this effect is only observed when the two discrete durations are tested together in a mixed session (Malapani et al, 1998b), and then only for durations in the seconds, not milliseconds, range (Koch et al, 2008). These results suggest that the migration effect is because of a faulty mnemonic representation of the pre-learned durations. In a follow-up study, Malapani et al (2002) dissociated the encoding and retrieval stages of the task and found that migration effects were because of faulty retrieval of the pre-learned durations during the reproduction phase. On the other hand, the initial encoding of stimulus duration into memory in nonmedicated PD patients led to overestimation of both short and long durations, suggesting that during duration encoding BG may have a role in determining the speed of the internal clock (see also Pastor et al, 1992).

\section{Functional Neuroimaging: Identifying Distributed Timing Networks}

Explicit timing. In contrast to the rather mixed results provided by the neuropsychological lesion literature, functional neuroimaging studies in healthy volunteers have consistently identified the BG in the representation of stimulus duration (Coull and Nobre, 2008; Meck et al, 2008). In fact, timing-induced BG activity has been shown to be independent of the stage of motor processing (preparation or execution) being timed (Bueti et al, 2008b), the sensorimotor context (synchronization or syncopation) in which the timed interval was learned (Jantzen et al, 2007; Jantzen et al, 2004), the duration range (sub- vs supra-second) being timed (Jahanshahi et al, 2006), the motor effector (left/right hand or speech) used to perform a rhythmic timing task (Bengtsson et al, 2005), and the sensory modality (auditory/visual) in which timed stimuli were presented (Shih et al, 2009). In all of these studies, timing activated dorsal, rather than ventral, striatum. Taken as a whole, these results are suggestive of a centralized, context-independent, supramodal timer localized in the dorsal striatum of the BG.

Of course, it is possible that there is functional specialization for discrete aspects of timing performance (eg, motor/perceptual; sub/suprasecond; auditory/visual markers) within distinct nuclei of the BG. The areas most commonly activated by timing tasks are the putamen and caudate nucleus of the dorsal striatum, and its target site within the BG, the globus pallidus. The high spatial resolution of functional magnetic resonance imaging (fMRI) would lend itself perfectly to such a question. Although this has not yet been formally explored, data from several wellcontrolled fMRI studies are plotted in Figure 1 as a function of the perceptual or motor nature of the timing task. First, the figure shows that timing more often activates the putamen rather than the caudate nucleus of the dorsal striatum. Second, the clusters of activation suggest that motor timing tasks tend to activate more lateral regions of basal ganglia, predominantly in the putamen (dorsolateral striatum), whereas perceptual tasks tend to activate more medial regions, including the caudate and globus pallidus. This figure is also suggestive of a rostrocaudal gradient within dorsal striatum, with perceptual tasks activating more rostral areas (anterior putamen and caudate nucleus) and motor timing tasks activating more caudal regions
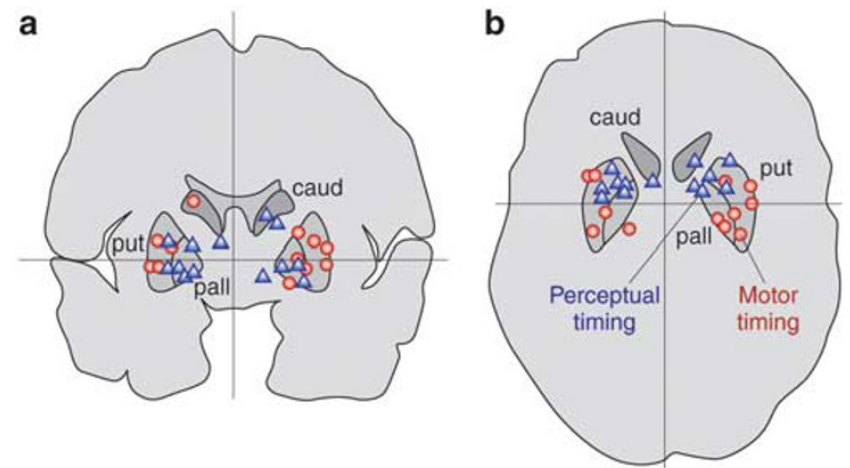

Figure 1. Timing in the basal ganglia. Each point represents the site of peak amplitude of a timing-induced activation cluster taken from a representative sample of motor (Bueti et al, 2008b; Garraux et al, 2005; Jahanshahi et al, 2006; Jantzen et al, 2007; Lewis et al, 2004; Rao et al, 1997; Spencer et al, 2007) and perceptual (Coull et al, 2004, 2008a; Ferrandez et al, 2003; Harrington et al, 2010; Lewis and Miall, 2003a; Livesey et al, 2007; Morillon et al, 2009; Nenadic et al, 2003; Pouthas et al, 2005; Rao et al, 2001; Shih et al, 2009; Tregellas et al, 2006) timing studies in healthy volunteers (motor=red circles; perceptual=blue triangles). Activations are located in putamen (put), caudate nucleus (caud), or globus pallidus (pall), and are shown on either (a) coronal or (b) transverse views of a standardized template brain. The intersection point of the red cross-hair represents $x, y, z=0,0,0 \mathrm{~mm}$ in the Montreal Neurological Institute (MNI) coordinate space. These templates should be considered as 'glass' brains and activations were actually spread in either the (a) rostral/caudal (range $y=-15$ to $18 \mathrm{~mm}$ ) or (b) dorsal/ventral (range $z=-9$ to $20 \mathrm{~mm}$ ) direction. SMA and cerebellum activations from the same sample of studies are plotted in Figures 2 and 3. Cortical (eg, prefrontal and premotor) activations from the majority of these studies are illustrated in Coull and Nobre (2008). 
(putamen). This pattern of activation corresponds well to the known functional specialization of sensorimotor (lateral putamen) and associative (caudate) areas of the BG (Nakano et al, 2000).

However, the BG does not act in isolation. In contrast to lesion or TMS studies, the whole-brain approach of fMRI reveals that BG are most often co-activated with a variety of anatomically discrete cortical regions. This activation of a functionally integrated network of corticostriatal regions by timing, rather than a single anatomically specific area, is probably the most likely explanation for the lack of a neurological or psychiatric disorder that is uniquely characterized by temporal deficits. The particular network of cortical regions typically activated by timing tasks (supplementary motor area, prefrontal cortex) corresponds well to the motor and dorsolateral prefrontal corticostriatal loops described by Alexander et al (1986). Yet, although the same key regions crop up time and time again, different combinations of nodes in the timing network can be coactivated depending on the particular task context. Indeed, one of the most hotly debated topics in the timing literature at the moment is whether time is represented in a contextdependent or -independent manner in the brain (Ivry and Schlerf, 2008).

Jantzen and colleagues provided one of the first demonstrations of context-dependent differences in timing-related brain activity using variations of the paced finger tapping task. During the continuation phase, patterns of regional brain activity differed depending upon whether the pacing rhythm was sychronized to occur on or off the beat (Jantzen et al, 2004) or had been specified using auditory or visual metronomes (Jantzen et al, 2005). Crucially, these regional differences appeared despite the fact that during the continuation phase timing occurred in the absence of sensory stimuli. In other words, internal representation of a time interval differed depending upon the way in which it had been encoded, suggesting that representations of duration are rooted in context-specific processing areas rather than being represented in a supramodal centralized timer. However, a later study (Jantzen et al, 2007) uncovered evidence for both contextdependent and context-independent representations of time. Specifically, the cerebellum, premotor cortex, and preSMA were differentially activated during the continuation phase depending upon whether the preceding pacing rhythm had been on or off the beat, therefore reflecting context-dependent representations of time. However, SMA and BG were activated equally irrespective of whether the preceding pacing rhythm had been on or off the beat, reflecting more centralized, supramodal representations of time. These studies provide evidence that although various cortical regions may provide context-dependent representations of duration, BG and SMA have a more central, ubiquitous role in motor timing.

Because BG and SMA are traditionally considered to be integral to motor control, their activation during a motor timing task may not be that surprising. To conclude that these areas underlie timing of a more generalized nature, we need evidence that BG and SMA can also be activated by timing of a non-motor nature. The temporal discrimination task, in which subjects compare the duration (eg, same/ different; shorter/longer) of a probe sensory stimulus to that of a target stimulus previously stored in working or reference memory, taps perceptual, rather than motor, timing processes. Control tasks, requiring comparison of another, non-temporal, stimulus feature (eg, color, length, and brightness), account for activations linked to processes of non-interest, such as attention, working memory, or sensorimotor task demands. A comparison of timing with control tasks reveals areas uniquely engaged by perceptual timing. In general, temporal discrimination tasks preferentially activate an extended corticostriatal network, encompassing BG and, predominantly right-lateralized, prefrontal, superior temporal, and inferior parietal cortices (see, eg, Coull et al, 2004, 2008a; Ferrandez et al, 2003; Lewis and Miall, 2003a; Morillon et al, 2009; Rao et al, 2001; Shih et al, 2009). Unfortunately, however, timing tasks are often more difficult than control tasks, as indexed by significantly lower levels of performance. This performance difference makes it difficult to conclude that activations are specifically related to timing and not to mental effort in general. However, if extra care is taken to match performance levels on the control and timing tasks (Coull et al, 2004, 2008a; Morillon et al, 2009; Nenadic et al, 2003; Rao et al, 2001) a core network of pre-SMA, BG, and right inferior frontal cortex is most commonly found. Indeed, even if the control task is made more difficult than the temporal task (Livesey et al, 2007), timing-induced activation of BG and inferior frontal cortex still remains. And if temporal task demands are increased, either by lengthening the duration to be timed (Pouthas et al, 2005) or by reducing the temporal discriminability of two comparison stimuli (Tregellas et al, 2006), activity increases are localized once again to the core network of SMA, BG, and frontal cortex.

This core network has been functionally deconstructed by event-related fMRI studies, such that discrete anatomical components can be associated with distinct stages of the pacemaker-accumulator model. SMA is engaged by the online timing (or accumulation) of a stimulus duration that is currently unfolding in time (Coull et al, 2008a; Morillon et al, 2009; see also Macar et al, 1999 for electrophysiological evidence), consistent with its aforementioned role in timing externally specified stimulus duration. BG on the other hand, are activated particularly during the encoding phase of perceptual timing tasks in which the timed stimulus duration is stored into memory for later recall (Coull et al, 2008a; Harrington et al, 2004a, 2010; Rao et al, 2001). Moreover, a significant co-variation between BG activity and timing performance (Coull et al, 2008a) suggests that the amplitude of activity in this area mediates the depth of encoding of stimulus duration. These data fit well with neuropsychological data in PD patients showing that their timing deficits seem to be related specifically to mnemonic aspects of timing (Malapani et al, 1998b, 2002; 
Koch et al, 2008). However, the precise role of frontal cortex in timing is less clear. In parallel with superior temporal cortex, it has been associated with later processing stages, such as integration of the accumulated tally of pulses (Morillon et al, 2009) or comparison with a memorized standard (Rao et al, 2001; Coull et al, 2008a). Electrophysiological data from monkey prefrontal cortex substantiate this claim, indicating that frontal cortex is implicated in the 'comparison... and... accumulation... of clock pulses' (Genovesio et al, 2009).

Integrating the variety of areas typically activated by perceptual timing with those typically activated by motor timing, we converge more specifically upon BG and SMA. To be more anatomically precise, the areas most commonly activated are the dorsal striatum (and occasionally associated globus pallidus) of the BG (Figure 1) and the rostral portion of SMA, known as preSMA (Figure 2). Both BG and SMA are consistently (and often selectively) activated during motor tasks of temporal reproduction (see, eg, Bueti et al, 2008b; Jahanshahi et al, 2006; Jantzen et al, 2004; Lewis et al, 2004; Rao et al, 1997) or perceptual tasks of temporal discrimination (see, eg, Coull et al, 2004; Cunnington et al, 2002; Grahn and Brett, 2007; Grahn and McAuley, 2009; Harrington et al, 2010; Rao et al, 2001; Shih et al, 2009). However, one feature shared by all of these studies was that the duration to be timed was externally specified by sensory stimuli (eg, the interval between two tones or the duration of a visual stimulus). On the other hand, when subjects were required to produce their own internal representation of a variable time interval (Cunnington et al, 2002; Garraux et al, 2005) the BG alone were activated. This suggests a differential role for BG and SMA

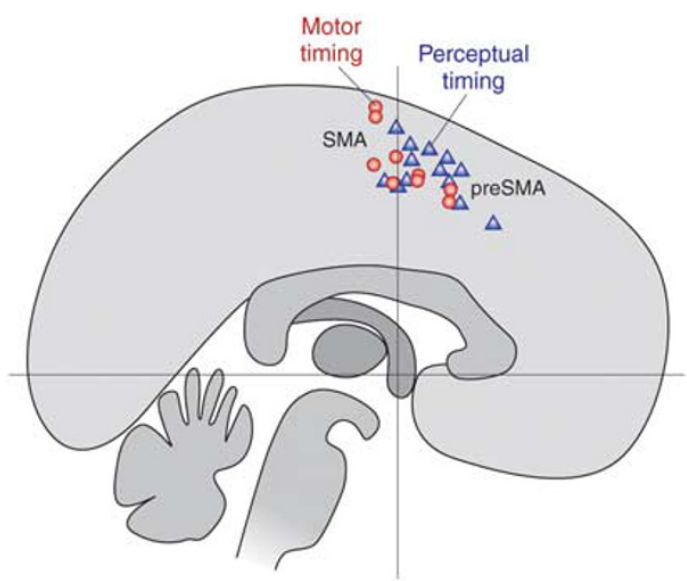

Figure 2. Timing in the supplementary motor area (SMA). Each point represents the site of peak amplitude of a timing-induced activation cluster taken from a representative sample (see Figure 1 for details) of motor (red circles) and perceptual (blue triangles) timing studies in healthy volunteers. Activations are located in SMA or preSMA, and are shown on a midsaggital view (range of activations $x=-20$ to $24 \mathrm{~mm}$ ) of a standardized 'glass' brain. See Figure 1 for further details. The red vertical line corresponds to the anatomical division between SMA and preSMA. in the representation of temporal intervals that are internally or externally specified, respectively. Of course, the majority of timing studies probably engage a mixture of externally and internally specified temporal representations; often, subjects time an externally specified interval and then store (perceptual timing) or reproduce (motor timing) an internal representation of that interval, thus explaining why so many studies report activation of both BG and SMA.

Internally determined representations of time have also been linked to the cerebellum, an area that has consistently been implicated in timing, at least timing of short subsecond durations, by lesion and TMS studies (see the section, Lesion and TMS Studies in Humans: Identifying Critical Timing Regions). Spencer et al (2007) compared motor timing of paced finger tapping when the movement required either an explicit (discrete movement) or implicit (continuous movement) representation of duration. Cerebellum, but not SMA, was significantly more activated during discrete than continuous movements. The only difference between these conditions was the inclusion of a self-determined short pause $(\sim 200-400 \mathrm{~ms})$ between movements in the discrete condition. Cerebellar activity for internally determined sub-second timing complements its role in timing of sub-second durations that were externally specified by sensory stimuli (Koch et al, 2007; Lee et al, 2007; Lewis and Miall, 2003a; Penhune et al, 1998; Tregellas et al, 2006, but see Jahanshahi et al, 2006). In a review of the neuroimaging literature several years ago, investigators suggested that the cerebellum was linked specifically to motor representations of sub-second durations (Lewis and Miall, 2003b). Accumulating evidence since then has continued to support the context-dependent role of the cerebellum: it is activated principally by motor timing tasks (Penhune et al, 1998; Jäncke et al, 2000; Jantzen et al, 2004; Bengtsson et al, 2005; Jahanshahi et al, 2006; Bueti et al, 2008b) but only rarely by perceptual timing tasks (see Figure 3), and then only when these implicate sub-second durations (Lewis and Miall, 2003a; Tregellas et al, 2006; Shih et al, 2009; Morillon et al, 2009; although see Harrington et al, 2004b).

Implicit timing: temporal prediction. The cerebellum has also been implicated in studies of temporal prediction, in which the task goal is not an overt estimate of duration but, rather, a fast and/or accurate response to a stimulus appearing at an expected time. As such, timing mechanisms are engaged automatically (implicitly) rather than deliberately (explicitly). In these tasks, temporally informative cues allow the subject to predict when a target stimulus or event will occur, so as to optimize behavior. Cues can take the form of temporally structured stimuli ('exogenous' cues), such as the constant velocity of an approaching car, or prelearned arbitrary symbols ('endogenous' cues), such as the interval between the amber and red traffic lights. In the laboratory, both exogenous and endogenous temporal cues have been associated with cerebellar activity. Specifically, 


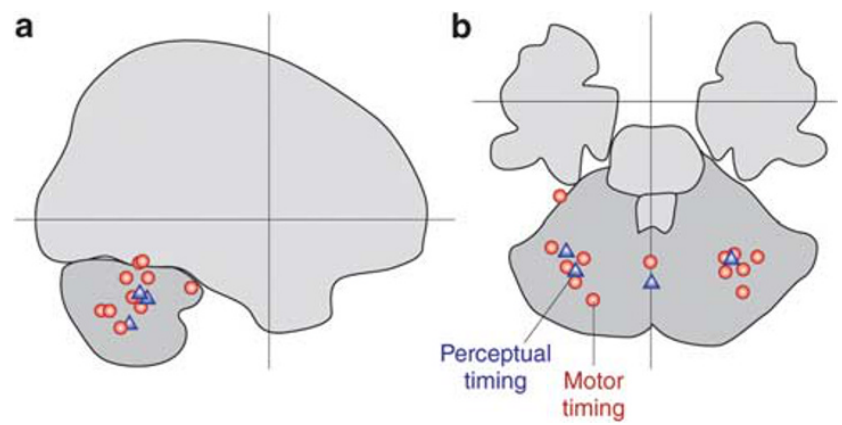

Figure 3. Timing in the cerebellum. Each point represents the site of peak amplitude of a timing-induced activation cluster taken from a representative sample (see Figure 1 for details) of motor (red circles) and perceptual (blue triangles) timing studies in healthy volunteers. Activations are shown on (a) lateral (range of activations $x=-23$ to $-39 \mathrm{~mm}$ in the left hemisphere and 30-42 $\mathrm{mm}$ in the right hemisphere) or (b) transverse (range of activations $z=-45$ to $-18 \mathrm{~mm}$ ) views of a standardized 'glass' brain. The two midline activations that can be seen on the transverse view are not included in the lateral view. See Figure 1 for further details.

posterior regions of lateral cerebellum were selectively activated by temporal, when compared with spatial, predictions when subjects used either the velocity of a dynamic visual stimulus (Beudel et al, 2009; O'Reilly et al, 2008) or symbolic temporal pre-cues (Coull and Nobre, 1998) to make temporal predictions. The cerebellum is thought to use forward modeling to predict the sensory consequences of motor behavior (Wolpert et al, 1998). These fMRI results show that the posterior cerebellum is also involved in forward modeling of purely perceptual stimuli, but only when the timing of the perceptual stimulus has to be predicted.

Using magnetoencephalography, researchers showed that activity in the cerebellar and left sensorimotor (in the region of anterior parietal cortex) regions correlated with the RT benefit of predictable temporal intervals (Martin et al, 2006). Indeed, left parietal cortex is another area that has consistently been associated with temporal predictability, whether of a motor or perceptual nature. Studies of both simple (Sakai et al, 2000) and choice RT (Dreher et al, 2002; Praamstra et al, 2006) have identified increased activity in left premotor and inferior parietal cortices when targets are presented after temporally predictable rather than random intervals, or when subjects use informative temporal precues to predict target onset (Coull and Nobre, 1998). These same regions are also activated by temporal prediction of a more perceptual nature, when subjects use temporal information inherent in the velocity of a dynamic visual stimulus to predict its final position (Assmus et al, 2003, 2005; Coull et al, 2008b; Field and Wann, 2005).

In summary, studies of temporal prediction (or implicit timing) activate cerebellum and left-lateralized premotor and parietal cortices (Coull and Nobre, 2008). (Note that we discuss studies of implicit timing of perceptual stimuli that demand either a motor response or a perceptual discrimination. In contrast, Spencer et al $(2003,2007)$ have shown that the cerebellum is not engaged by implicit (or 'emergent') timing of motor acts (although see Bo et al, 2008).) This contrasts clearly with activation of more midline structures such as BG and SMA, or right-lateralized frontal and temporal cortices, by explicit timing. However, there is one form of temporal prediction that has been associated with right-lateralized frontal activity (Coull, 2009). Fittingly, this is the temporal predictability provided by the very passing of time itself (Elithorn and Lawrence, 1955). The hazard function tracks the rising expectation over time that a sensory event will happen, given that it has not already happened. If an event does not occur when expected, temporal predictions can be updated and redirected toward the next possible time slot. In a cued RT task, in which pre-cues predict the time of target onset, RTs are faster for targets appearing when expected than for those appearing when least expected (Coull and Nobre, 1998). However, the RT cost for unexpectedly delayed targets is significantly less than that for unexpectedly premature targets. This is because of the predictive power of 'time's arrow': when the target does not appear when expected, temporal predictions can be updated on-line and resources directed toward the next potential time point, effectively removing the cost of the unexpected delay. Coull et al (2000) showed that delayed targets, when compared with either expected or premature targets, selectively activated right prefrontal and premotor cortex. This result was confirmed by Vallesi et al (2009) using a variable foreperiod paradigm, in which temporal expectancy for target appearance increases as a function of increasing delay ('foreperiod') between the warning cue and the target. When compared with a fixed foreperiod paradigm, in which temporal expectations did not evolve as a function of time in passing, the variable foreperiod task activated a region of right prefrontal cortex whose activity correlated significantly with the magnitude of the RT benefit afforded by increasing foreperiod length (Vallesi et al, 2009).

Taken as a whole, these results show that although the initial implementation of a fixed or entrained temporal expectancy recruits left parietal and premotor areas, the updating of this expectancy as a function of the flow of time itself recruits right prefrontal areas. Of course, right prefrontal areas are not only activated by the hazard function but also by explicit timing, as discussed above. Indeed, MacDonald and Meck (2004) have suggested that the neural substrates for explicit timing and the hazard function may overlap. One appealing way of reconciling these distinct data sets is to interpret right prefrontal activation in explicit timing tasks as indexing the updating of temporal representations with elapsing time. In explicit timing tasks, the current interval or duration is compared with a memorized standard. As the current interval unfolds, prefrontal cortex uses sensory feedback from stimulus presentation ('has the interval offset marker been presented yet?') to constantly update the comparison between current and memorized durations. This fits well with the monitoring role of the right prefrontal cortex (Henson et al, 1999; 
Petrides, 1996) and, more usefully, produces a testable prediction: right prefrontal cortex should be preferentially engaged when the current stimulus duration is longer, rather than shorter, than the memorized one. Although this hypothesis has not yet been tested with fMRI, electroencephalographic (EEG) evidence suggests that this is the case. Specifically, when the contingent negative variation (CNV), a slow-wave indexing temporal preparation, was measured over right frontal electrodes it increased steadily until the end of the ongoing stimulus duration, even if this was longer than the memorized target duration (Pfeuty et al, 2003). In contrast, if measured over left frontal (Pfeuty et al, 2003), parietal (Macar and Vidal, 2003), or premotor (Praamstra et al, 2006) electrodes, it increased only up until the memorized (or entrained) duration had been reached, even if the ongoing stimulus duration carried on beyond this point. These EEG data parallel the fMRI findings described above, showing right-lateralized activity for expectations that evolve as a function of currently elapsing time, but left-lateralized activity for fixed or entrained expectations.

Intriguingly, CNV activity recorded over medial frontal electrodes (in an area equivalent to SMA) was also linked to memorized, rather than ongoing, stimulus durations (Pfeuty et al, 2003), implicating this area in the representation of fixed temporal expectations. However, both EEG (Macar et al, 1999) and fMRI (Coull et al, 2008a) studies have linked SMA activity to the accumulation of time units, or 'pulses,' in a currently unfolding duration, suggesting that SMA activity should be linked more to ongoing, rather than memorized or expected, durations. However, a more recent fMRI study (Cui et al, 2009) has also reported a phasic increase in SMA activity at expected target durations, the amplitude of which varied as a function of temporal expectation. Notably, the SMA activity did not evolve dynamically as the duration unfolded, but instead momentarily indexed the integrated temporal expectancy that the target would have occurred at that particular moment. (Pfeuty et al, 2003 noted differences in CNV dynamics for filled durations vs empty intervals: the CNV rose steadily until the memorized duration for filled durations, but increased sharply at the memorized duration for empty intervals. This distinction may account for the phasic increase in SMA activity observed by Cui et al, 2009, who used empty intervals $v s$ the slow-rising medial frontal CNV observed by Pfeuty et al, 2003 who used filled durations.) Integration of cumulative temporal expectancies is an appealingly similar concept to the accumulation of temporal pulses. The involvement of SMA in both processes perhaps speaks to its more general role in the accrual of temporal information.

\section{Lesion Studies in Animals: The Role of Neurochemical Pathways}

Corticostriatal circuits. In animal studies, one commonly used timing task is the peak-interval (PI) procedure. The PI procedure is a temporal reproduction task that provides independent measures of accuracy (peak time), precision (peak spread), and motivation (peak rate) for durations in the seconds-to-minutes range for humans and other animals (see, eg, Church et al, 1994; Cheng and Meck, 2007; Hinton and Meck, 2004; Malapani et al, 1998b; Paule et al, 1999; Rakitin et al, 1998). In this procedure, subjects (eg, rats) are initially trained on a discrete-trials fixedinterval (FI) procedure, in which a signal (eg, light or sound) is turned on, the first lever press after the target duration has elapsed is reinforced and the signal is then turned off. Once well trained on the FI procedure, rats are presented with non-reinforced probe trials that are randomly interspersed among the FI trials. These probe trials last a relatively long time $(\mathrm{eg}, 3 \times$ the target duration $=$ FI value) and terminate independently of responding. On individual probe trials, subjects show their ability to time by centering a window of responding around the target duration. This is achieved by initiating a relatively constant rate of responding once a 'start' threshold is crossed and then continuing to lever press until a 'stop' threshold is crossed. These response thresholds are typically symmetrical, that is, they are placed at proportional distances from the target duration on both sides of the expected time of reinforcement. When averaging over the step functions obtained from individual probe trials, lever pressing can be seen to ramp up toward the target duration and then decrease in a fairly symmetrical manner, thus establishing a 'peak' or Gaussian-shaped response function for responding averaged over trials - hence the name of the procedure. It is from this Gaussian-shaped response function that the measures of peak time, peak rate, and peak spread are obtained (Church et al, 1994; Matell et al, 2006). The reliability and robustness of PI timing procedures have proven extremely valuable in electrophysiological studies (Matell et al, 2003) as well as in the evaluation of pharmacological and lesion effects (Matell et al, 2004, 2006; Meck, 2006a, b, 2007; Paule et al, 1999).

Functional mapping studies using lesions of specific brain regions followed by observation of subsequent behavioral deficits can provide an indication of which brain regions are critically involved in interval timing. For example, the effects of selective DA-depleting lesions using 6-hydroxydopamine microinjection into the substantia nigra pars compacta (SNC), caudate-putamen $(\mathrm{CPu})$, or the nucleus accumbens (NAS) have been used to evaluate the timing performance of rats trained on 10-s (eg, light signal) and 60-s (eg, sound signal) PI procedures. A double dissociation in the performance of these duration discriminations was found. Rats with post-training $\mathrm{CPu}$ lesions were unable to maintain temporal control of their behavior, suggesting complete insensitivity to signal duration after the lesion, but were able to show continued discrimination of the relative reward values of the light and sound signals that were associated with different delays by differentially modifying their response rates between trials. In contrast, rats with NAS lesions were able to show temporal control of 
their behavior by differentially modifying their response rates as a function of signal duration(s) within trials, suggesting no impairment of sensitivity to signal duration, but were unable to show discrimination of the relative reward value of a signal between trials (Meck, 2006b).

The SNC and $\mathrm{CPu}$ are both components of the nigrostriatal DA pathway, one that is also critical for regulating motor function. While damage to either one of these two regions leads to impairments in timing as shown in Figure 4, the specific contribution of each brain region can be further distinguished by observing whether the partial restoration of DA levels can lead to recovery of the lesion-induced timing deficits. With the administration of L-DOPA (a precursor of DA) in the same study (Meck, 2006b), only SNC-lesioned rats showed improvement in their timing functions, indicating that the SNC-lesioned rats were able to recover temporal control of behavior with the help of L-DOPA, but the CPu-lesioned rats did not show the same functional restoration with L-DOPA. Hence, one can infer that a minimal level of DA activity in nigrostriatal circuits is required to maintain relatively normal interval timing, but only with an intact $\mathrm{CPu}$. Accordingly, the neurons in the $\mathrm{CPu}$ region seem to be critical for a more specific aspect of temporal integration (eg, coincidence detection-Matell et al, 2003; Matell and Meck, 2004).
As part of the $\mathrm{BG}$, the $\mathrm{CPu}$ region provides the major input signals to the $B G$, including the pallidum and the subthalamic nucleus (STN). In a recent study in which the rat's STN was lesioned, researchers found that timing per se was not affected by the lesion (Wiener et al, 2008 ). The only 'impairment' observed in the lesioned rats was that they showed higher response rates long after the target duration had passed, an indication of increased impulsivity at times when no reinforcement is available. Because the STN is downstream of the $\mathrm{CPu}$, in which temporal processing in the $B G$ is thought to be occurring, one can infer that most timing information is processed before the STN. This explains why the STN-lesioned rats are still able to show normal timing functions and suggests that temporal integration and/or coincidence detection occurs before the STN, most likely by the medium spiny neurons (MSNs) in the $\mathrm{CPu}$ region.

In contrast to lesioning the nigrostriatal areas, lesion studies targeting the primary and secondary motor cortices (M1 and M2) that project to the BG do not seem to affect duration discrimination for actions such as lever pressing. As shown by Yin (2009), mice with M1 or M2 lesions were able to produce the required lever-press duration (eg, 400, 800 , or $1600 \mathrm{~ms}$ ) or sequence (eg, left $\rightarrow$ right or right $\rightarrow$ left). However, a recent study using monkeys reported that
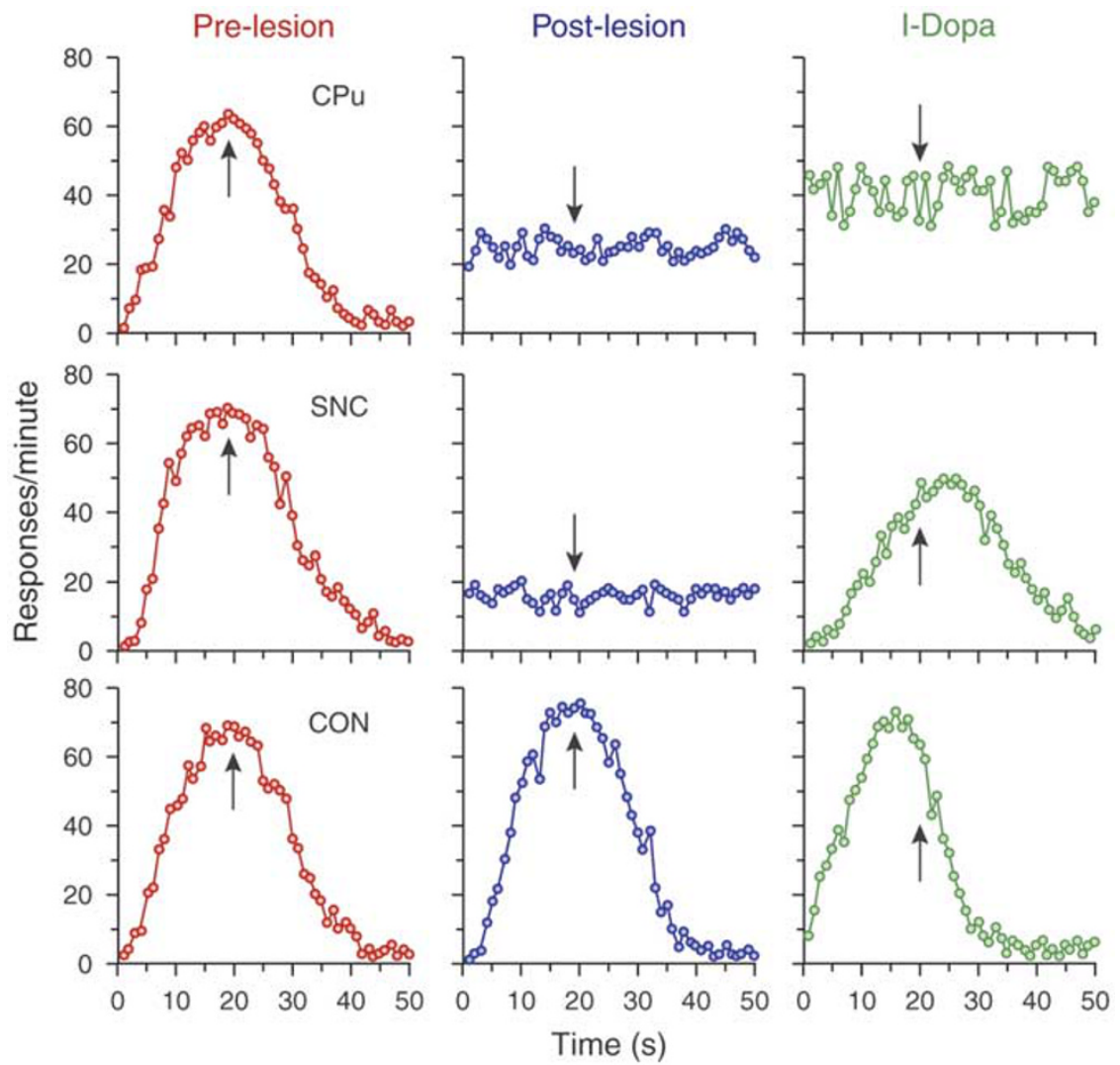

Figure 4. Timing deficits in nigrostriatal-lesioned rats. Mean lever-press rate (responses/min) as a function of signal duration (s) for rats trained on a 20-s PI timing procedure during three experimental phases. The preoperative timing data are shown in the left-hand column, the postoperative data are shown in the middle column, and the postoperative L-DOPA test data are shown in the right-hand column. Data for rats in the caudate-putamen (CPu) lesion group are shown in the top row, the data for the substantia nigra pars compacta (SNC) lesion group are shown in the middle row, and the data for the control lesion group are shown in the bottom row. Adapted from Meck (2006b) with permission. 
neurons in the SMA, an area comparable to M2 in mice, show spiking neural activity that correlated with the duration of actions (Mita et al, 2009). Yet, how these neural firing data reflect on the primary $v s$ secondary role of M2 in representing duration is unclear, as it is unknown whether SMA lesions impair timing behavior in monkeys or in humans (although see Halsband et al, 1993). As a consequence, further studies are required to disentangle the role of M2 in the temporal control of the action sequences used in most interval-timing experiments using animals. Electrophysiological data supporting the role of corticostriatal circuits in timing come from studies in rats and monkeys showing that striatal neurons encode specific durations in PI procedures (Matell et al, 2003) as well as in perceptual timing tasks in which one stimulus must be classified as being 'shorter' or 'longer' than a preceding stimulus (Chiba et al, 2008). Moreover, tasks in which subjects are able to form a temporal representation of the sequence of sensory and motor events show specific involvement of prefrontal and striatal neurons (Jin et al, 2009). A diagram of the proposed connections within the corticostriatal circuit is presented in Figure 5.

Basal forebrain cholinergic circuits. A different set of lesion studies were conducted to identify the role of cholinergic pathways in the temporal control of behavior. Among the relevant cholinergic pathways, the medial septal area (MSA) provides cholinergic inputs to the hippocampus, whereas the nucleus basalis magnocellularis (NBM) provides cholinergic inputs to the frontal cortex (Mesulam et al, 1983). In two series of experiments, Meck et al (1987) showed that rats given lesions of the frontal cortex or the NBM showed persistent rightward shifts (ie, increase of peak time) in their timing functions in the PI procedure compared with their performance before surgery or with the performance of control rats. In contrast, rats given fimbriafornix (FFx), hippocampal, or MSA lesions showed persistent leftward shifts (decrease of peak time) in their timing functions as shown in Figure 6. A similar leftward shift has been observed after dorsal hippocampal lesions in mice (see, pp 175 in Balci et al, 2009). One interesting phenomenon observed here is that the timing effects after lesions to any part of these cholingergic pathways take several sessions of behavioral training to emerge, whereas the effects of lesioning nigrostriatal circuits can be observed immediately during the first postsurgery session. The slow build-up of changes in the timing performance after lesions

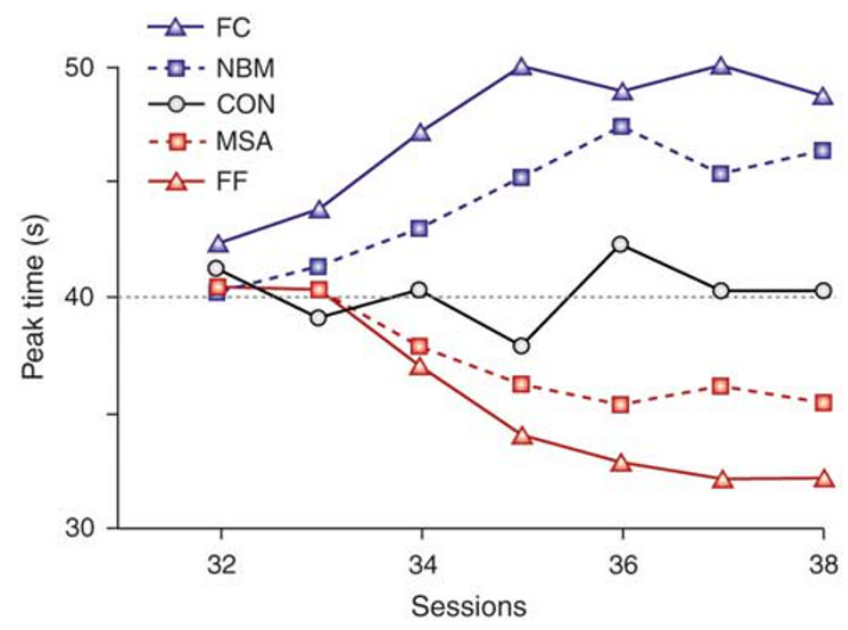

Figure 6. Timing deficits in MSA- and NBM-lesioned rats. The postoperative timing performance of rats in a peak-interval procedure. Median peak times are plotted as a function of the first 7 days (sessions 32-38) of peak-interval retraining for rats with control operations (CON), lesions of the frontal cortex (FC), of the nucleus basalis magnocellularis (NBM), of the medial septal area (MSA), and of the fimbria-fornix (FF). Adapted from Meck et al (1987).
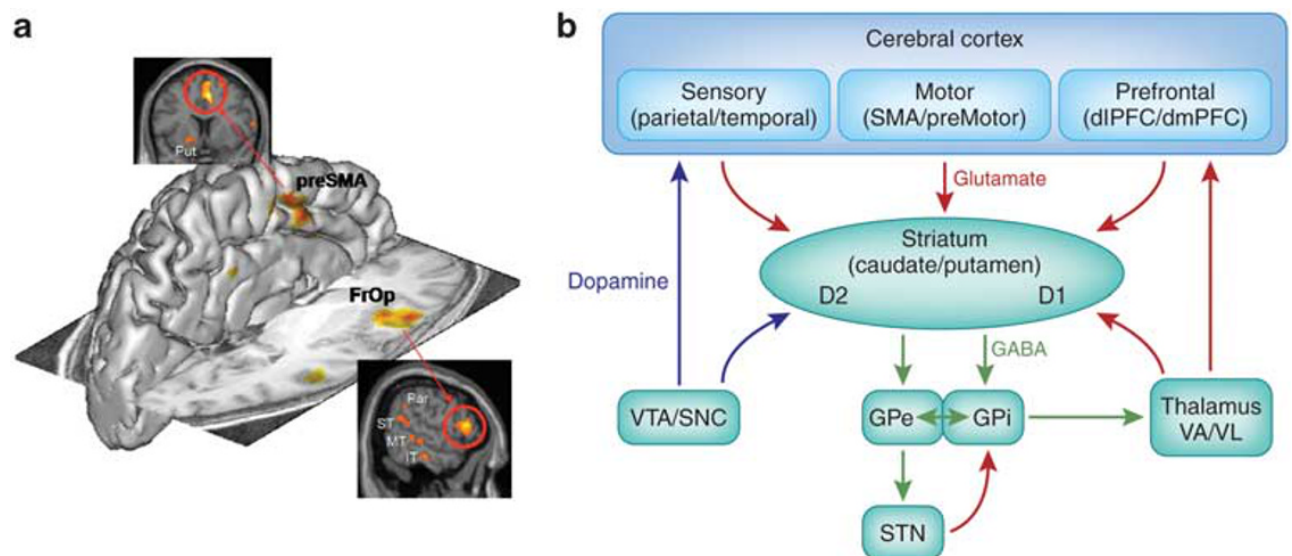

Figure 5. Corticostriatal circuits for interval timing. Human functional imaging data (a) showing the corticostriatal circuits (b) implicated in interval timing. Blue lines represent dopaminergic input, green lines represent GABAergic input, and red lines represent glutamatergic input. FrOp, frontal operculum; GPe, globus pallidus external capsule; GPi, globus pallidus internal capsule; preMotor, premotor cortex; dIPFC, dorsolateral prefrontal cortex; dmPFC, dorsomedial prefrontal cortex; Par, inferior parietal cortex; Put, putamen; SMA, supplementary motor area; SNC, substantia nigra pars compacta; STN, subthalamic nucleus; VL, ventral lateral nucleus of the dorsal thalamus; VA, ventral anterior nucleus of the dorsal thalamus. IT/MT/ST, inferior/middle/ superior temporal cortex. Figure $5 \mathrm{a}$ is adapted from Coull et al (2004). 
of the cholinergic system suggests that the gradual horizontal shift of their timing functions may be because of alterations in the encoding of temporal memories rather than a direct effect on actual timing mechanisms, which would induce immediate timing deficits. Hence, frontohippocampal circuits seem to cooperate to achieve optimal representation in temporal memory and any imbalance in the fronto-hippocampal circuits will distort the representation in temporal memory, without affecting the speed of the internal clock. In contrast, clock speed seems to be more related to functioning of the nigrostriatal DA pathway. Interestingly, lesions of the NBM and frontal cortex (but not MSA and hippocampus) selectively reduced the modulatory control of clock speed produced by dopaminergic agonists and antagonists (eg, methamphetamine and haloperidol), which are likely to be mediated by dopamine $\mathrm{D} 2$ receptors located on corticostriatal neurons (Meck, 1986, 2006a).

In summary, the effects of cholinergic manipulations (eg, MSA-/FF-lesioned and NBA-FC-lesioned animals as well as acetylcholine (Ach) agonists and antagonists) seem to be related to changes in cortical and hippocampal influences on striatal function (Meck, 2002a,b). These interactions may involve cholinergic interneurons in the striatum, but are primarily related to compensatory mechanisms governing the competition between the medial temporal lobe, frontal lobe, and BG (see, eg, Poldrack and Packard, 2003). Sodium-dependent high-affinity choline uptake (SDHACU) in the frontal cortex and hippocampus has been shown to be proportional to the absolute error in the contents of temporal memory for rats trained in the PI procedure. A comparison of these cholinergic effects in the PI procedure $v s$ a random-interval procedure in which time was irrelevant showed that changes in SDHACU are dependent upon the predictability of the programmed time of reinforcement and the presumed striatal activity centered around the expected time of reinforcement. As a consequence of feedforward mechanisms, cortical and/or hippocampal activity has been proposed to modify the time window of striatal activity such that reinforcement can come to be expected at an earlier or later time, proportional to the actual target duration (Meck, 2002a; Ondracek et al, 2008).

Cortico-cerebellar circuits. Parallel corticostriatal and cortico-cerebellar circuits have been proposed to subserve different ranges of interval timing, with sub-second durations being mediated by cerebellar circuits and suprasecond durations being mediated by striatal circuits, as described by Meck (2005). Support for this proposal comes from a recent study showing that lesions of the interpositus nuclei of the cerebellum have relatively little effect on time perception with durations in the 2-8s range (Callu et al, 2009). In contrast, other studies using similar duration bisection procedures have shown detrimental effects for counting and timing in rats after lesions to the cerebellar vermis and hemispheres for durations in the millisecond range (Breukelaar and Dalrymple-Alford, 1999).

\section{NEUROCHEMICAL BASIS OF TIMING}

\section{Psychopharmacological Investigations in Healthy Volunteers}

In a series of studies spanning two decades, Rammsayer and colleagues have methodically tested the effects of various pharmacological manipulations on timing performance in healthy volunteers. The explanatory power of their findings lies partly in the recurrent use of the same perceptual timing paradigm across a range of different drugs. In brief, their paradigm requires subjects to estimate the relative duration (shorter/longer) of pairs of auditory tones, in either the millisecond $(\sim 50 \mathrm{~ms})$ or seconds $(\sim 1 \mathrm{~s})$ range. Perceptual timing accuracy is measured by difference thresholds, which indicate by how many ms the durations of the two tones have to differ for the subject to be able to discriminate them at a criterion level (75\% correct). Studies reliably showed a significant effect of an acute $3 \mathrm{mg}$ dose of the D2 receptor antagonist haloperidol on accuracy. Specifically, haloperidol reduced temporal sensitivity in both the milliseconds and seconds range (Rammsayer, 1989a, b; Rammsayer, 1993, 1997a, b, 1999), whereas pergolide, a D1/D2 receptor agonist, improved temporal sensitivity in the milliseconds range (Rammsayer, 2009). On the other hand, neither the DA precusor L-DOPA (Rammsayer, 1989a, b) nor AMPT (Rammsayer and Vogel, 1992), which blocks the conversion of tyrosine to L-DOPA, affected performance in either the milliseconds or seconds range. This strongly suggests that dopaminergic modulation of timing is mediated through an action on the dopaminergic receptor, rather than through DA synthesis more generally. Given the pharmacological properties of haloperidol, and complementary experiments in animals using a variety of DA receptor antagonists (MacDonald and Meck, 2006; Meck, 1986, 1996), the D2 receptor is the most likely candidate. However, the D2 antagonist remoxipride impaired timing only in the seconds and not milliseconds range (Rammsayer, 1993, 1997a), whereas the D2 antagonist sulpiride had no effect at all on temporal sensitivity, in either the milliseconds or seconds range (Meyer-Lindenberg et al, 1997; Rammsayer, 1997a). Rammsayer (1993, 1997a) explained these discrepant findings in terms of differential receptor binding properties: remoxipride (Nadal, 2001) and sulpiride (Racagni et al, 2004) preferentially block D2 receptors in the mesolimbic DA system, which projects from the midbrain ventral tegmental area to the nucleus accumbens of the BG (ventral striatum), whereas haloperidol blocks D2 receptors in all DA systems, including the nigrostriatal system that projects from the midbrain substantia nigra to the caudate and putamen of the BG (dorsal striatum). He concluded that the dopaminergic modulation of timing, at least in terms of temporal sensitivity in the milliseconds range, was likely to be modulated specifically by activity in the nigrostriatal, rather than mesolimbic, DA system.

The nigrostriatal system forms part of the cortico-BGthalamocortical motor loop (Alexander et al, 1986) and is 
compromised in motor disorders such as PD. It is therefore rather paradoxical that although $3 \mathrm{mg}$ haloperidol was consistently shown to impair perceptual timing, it had no effect on paced finger tapping, a measure of motor timing performance. Despite a significant haloperidol-induced slowing of motor speed, as measured by a speeded tapping task (ie, as many taps as possible in $30 \mathrm{~s}$ ), there was no effect of haloperidol on paced finger tapping, in which taps had to be precisely timed to occur at regular (one per second) intervals (Rammsayer, 1997b). If the dopaminergic modulation of timing was underpinned by activity specifically in the nigrostriatal loop, then it would seem reasonable to expect effects to be even stronger in tasks of motor timing than of perceptual timing. Researchers have found evidence for deleterious effects of chronic haloperidol treatment on motor timing, such that haloperidol slowed temporal reproduction of multisecond durations (Lustig and Meck, 2005). However, there are, as yet, no studies of the acute effects of haloperidol on motor timing (alone or in comparison with perceptual timing) in healthy volunteers.

Rammsayer and colleagues have also tested the effects of single doses of several non-dopaminergic drugs on the same task of perceptual timing. Sedative doses of the benzodiazepine midazolam, sufficient to impair short-term memory (Rammsayer, 1999) or slow speed of information processing (Rammsayer, 1992), had no effect on timing in the milliseconds range but significantly impaired performance in the seconds range. Similarly, the selective noradrenaline reuptake inhibitor, reboxitine, which increases noradrenaline concentration, significantly improved timing in the seconds, but not milliseconds, range (Rammsayer et al, 2001). Finally, the glutamatergic $N$-methyl-D-aspartate (NMDA) receptor antagonist memantine, pharmacologically similar to ketamine, impaired seconds range, but not milliseconds timing (Rammsayer, 2006). Timing in the range of seconds requires support from accessory processes, such as working memory or sustained attention (Brown, 2006; Fortin and Rousseau, 1998; Michon, 1985; Zakay and Block, 1996). Working memory and sustained attention have repeatedly been shown to be compromised by administration of benzodiazepines (Curran, 1991), noradrenergic drugs (Coull et al, 1995a,b), or ketamine (Morgan and Curran, 2006), most likely because of modulation of activity in the prefrontal and other cortical areas (Coull et al, 1999a,b; Honey et al, 2004, 2005). Rammsayer therefore concluded that seconds range timing could be disrupted by any drug that impaired attentional (Rammsayer et al, 2001) or mnemonic function (Rammsayer, 1999). On the other hand, disruption of milliseconds as well as seconds range timing by the dopaminergic antagonist haloperidol speaks to a more selective role for D2 receptors in perceptual timing, and perhaps even more specifically those D2 receptors that are located in the nigrostriatal DA system. More generally the differential effects of various drugs on millisecond $v s$ seconds range timing supports the proposition that subsecond vs suprasecond timings are distinct processes
(Ivry and Schlerf, 2008) that can be differentiated not only neuroanatomically (Lewis and Miall, 2003b) and physiologically (Karmarkar and Buonomano, 2007) but also pharmacologically.

The potentially therapeutic effects of serotonergic (5-HT) drugs in psychiatric disorders such as schizophrenia has led to an increasing interest in the modulatory effects of serotonin on dopaminergic function in the mesolimbic and nigrostriatal systems of the BG (Kapur and Remington, 1996). Interestingly, in parallel to investigations of dopaminergic modulation of timing, a large body of work in rats has shown that modulation of the 5-HT2 receptor system in particular also interferes with timing behavior (Ho et al, 2002) including temporal discrimination of discrete intervals (Asgari et al, 2005, 2006). In humans, Rammsayer (1989b) reported some early evidence that the serotonergic drugs fluoxetine and ritanserin could slightly improve perceptual timing performance in the sub-seconds range. More recently, Wittmann et al (2007; Wackermann et al, 2008) examined the effects of the hallucinogenic psilocybin, a 5-HT2A agonist, on motor timing in the time range of seconds. Psilocybin impaired both explicit and implicit measures of motor timing, as measured by a temporal reproduction task and the synchronization phase of the paced finger tapping task, respectively. However, effects were observed only for longer multisecond durations, with no effect on durations between $700 \mathrm{~ms}$ and $2 \mathrm{~s}$ (Wittmann et al, 2007). This dissociation led the researchers to conclude that psilocybin-induced timing dysfunction was because of modulation of the working memory and sustained attention processes that underpin timing of long compared with short durations.

However, the neurochemical basis for this timing effect is uncertain. Psilocybin does not only directly bind to 5-HT2A receptors but also indirectly increases DA concentration in the dorsal striatum of the BG, as measured by decreased D2 receptor occupancy in an [11C] raclopride PET study (Vollenweider et al, 1999). Moreover, the positive symptoms of psilocybin-induced psychosis can be attenuated by the dopaminergic D2 antagonist haloperidol (Vollenweider et al, 1998), suggesting that psilocybin's psychotic effects could actually be a consequence of abnormal dopaminergic function. Similarly, the psilocybin-induced timing deficits reported by Wittmann et al (2007) could actually be underpinned by an indirect dopaminergic, rather than direct serotonergic, mechanism.

\section{Psychopharmacological Studies in Animals}

Dopaminergic effects on the clock pattern. In animal studies, numerous lines of evidence have shown that brain DA levels are related to interval timing, in particular, the speed of the internal clock (see, eg, Meck, 1986, 1996; Williamson et al, 2008). The evidence primarily comes from studies in which rats were given systemic injection of indirect DA agonists, such as methamphetamine or cocaine. After injection, the rats showed a horizontal leftward shift in 
their timing functions in the PI procedure. When the same rats were administered DA antagonists (eg, haloperidol or raclopride), they showed a horizontal rightward shift (Buhusi, 2003; Buhusi and Meck, 2002; Cheng et al, 2007a, b; MacDonald and Meck, 2005, 2006; Maricq et al, 1981; Maricq and Church, 1983; Matell et al, 2004, 2006; Meck, 1983, 1986, 2006a). One major characteristic of dopaminergic drugs in changing timing and time perception is that the magnitude of the horizontal curve shift is proportional to the criterion time that subjects are trained to classify or reproduce. For example, a shift of $2 \mathrm{~s}$ in a PI 20 -s procedure will be doubled to a shift of $4 \mathrm{~s}$ in a PI $40-\mathrm{s}$ procedure after injection of dopaminergic drugs. This proportional shift indicates that the dopaminergic drug affects the speed of the internal clock (ie, a 10\% increase or decrease in the clock speed). Another way of showing selective psychopharmacological effects on clock speed is that the results follow a pattern of behavioral change collectively termed the 'clock pattern'. In brief, the 'clock pattern' shows the following three phases: (1) If a drug affects clock speed, it induces immediate horizontal shifts (rightward or leftward) in timing functions in the first session. (2) With repeated (chronic) drug administration, subjects should gradually re-normalize their timing functions such that functions would return to baseline level regardless of continued drug administration. This gradual renormalization is because of the rescaling of the stimulus duration and not to the development of tolerance (Meck, 1996). Finally, (3) a rebound effect should be observed after drug administration is discontinued such that the response functions are temporarily shifted in the opposite direction of the initial drug effect because of a 'mismatch' between the renormalization in memory and the change in clock speed after removal of the drug.

In addition to the 'clock pattern' observed after acute or chronic administration of dopaminergic drugs, genetic modifications of the DA transporter (DAT) involving DAT 'knockdown' or 'knockout' mice have shown that the resulting elevation in DA in the synaptic cleft can also alter PI timing functions in both homozygous and heterozygous mice compared with wild-type mice (pp 179 in Balci et al, 2009). Taken together, these patterns of change in the horizontal placement of interval-timing functions, induced either by DA drugs that temporarily block the DAT (eg, cocaine) or genetic alterations in the DAT, indicate that the DA system is critically involved in the timing and modulation of clock speed for durations in the seconds-to-minutes range (Meck, 1996 - but see Gooch et al, 2007; Rammsayer, 1999).

Acetylcholine and the memory pattern. In contrast to the clock pattern that is primarily related to the effective level of DA, drugs that target central cholinergic pathways have been found to induce a different change in timing function that is referred to as the 'memory pattern.' The main difference between the 'memory pattern' and the 'clock pattern' is that acute administration of cholinergic drugs has no immediate effect on the horizontal placement of timing functions during the first few injection sessions. However, with chronic administration, the timing functions would gradually be shifted to the right by cholinergic antagonists such as atropine or to the left by cholinergic agonists such as physostigmine (Meck, 1983; Meck and Church, 1987). Upon cessation of drug administration, the psychophysical functions typically remain in the shifted position(s) for several sessions and then gradually return to normal with additional training under saline control (Meck, 1996). This 'memory pattern' induced by cholinergic drugs is dramatically different from the 'clock pattern' induced by dopaminergic drugs. However, the drug-induced 'memory pattern' is consistent with the MSA and NBM lesion data reviewed above. That is, the persistent leftward shift because of chronic administration of a cholinergic agonist (eg, physostigmine) is similar to the results of lesions of the FFx or MSA. On the other hand, the persistent rightward shift after chronic administration of cholinergic antagonists (eg, atropine) is consistent with lesions of the frontal cortex or the NBM (Meck et al, 1987; Meck, 2006a). A more detailed analysis of the 'clock' and 'memory' patterns described here is provided by Hinton and Meck (1997) and Meck (1996; 2002a, b, 2006c).

Habit formation and DA-glutamate interactions. It has recently been reported that with extended training, the neural mechanism of interval timing transitions from a 'DA-sensitive' to a 'DA-insensitive' state as revealed by administration of methamphetmaine (MAP) to rats that had received different levels of baseline training using the PI procedure (Cheng et al, 2007b). After extended training (eg, $>120$ daily sessions), MAP induced general behavioral disruption, but failed to produce the standard clock speed effect (eg, proportional leftward shift in peak time as illustrated in Figure 7). This finding suggests that under certain conditions, interval timing may be considered a type of conditioned behavior that follows the rule of habit formation, which is a major component of addictive behavior (see Kalivas, 2008) and is also related to altered neural responses in the dorsal striatum (Takahashi et al, 2007; Yin et al, 2004, 2008, 2009). Moreover, Cheng et al (2007a) found that a combined injection of ketamine and cocaine can 'unlock' the reduced clock speed effect of cocaine or methamphetamine in rats after habit formation, as illustrated in Figure 8. That is, cocaine administration can produce the typical clock speed effects in overtrained rats as long as it is paired with a low dose of NMDA antagonist such as ketamine. The 'unlocking' effect of ketamine in this case suggests that there are DA-glutamate interactions that lead to a 'DA-insensitive' state after habit formation. These results highlight a potential mechanism for explaining how glutamate interacts with the DA pathways when subjects are in a pathologically addictive state. Furthermore, it also suggests that the glutamatergic inputs from the cortex and the thalamus to the dorsal striatum may have a role in habit formation, drug addiction, and interval timing (as recently outlined by Cheng et al, 


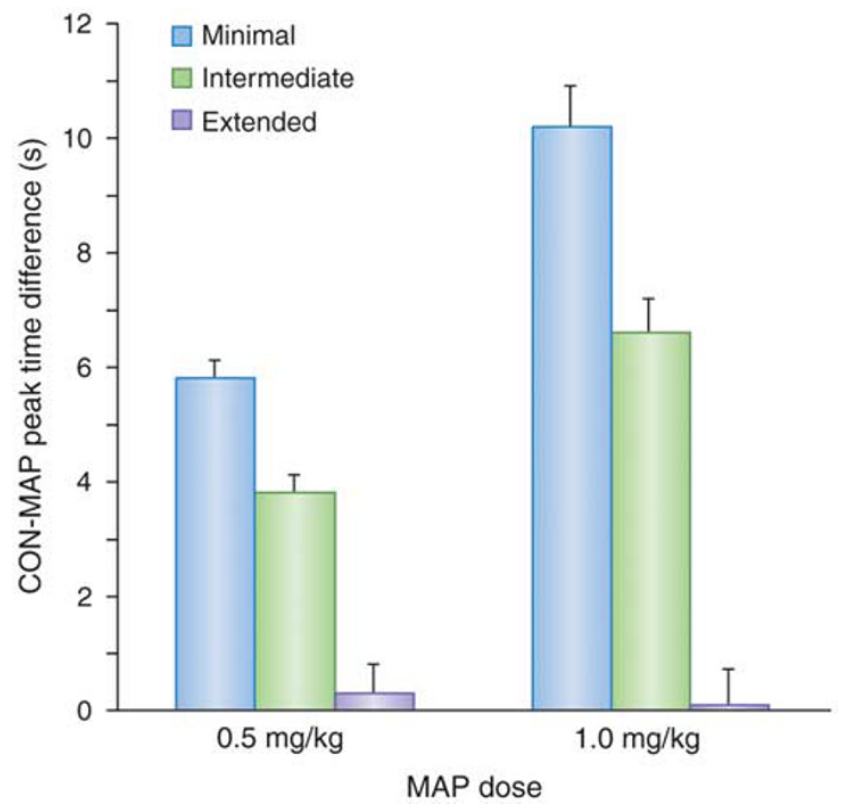

Figure 7. Habit formation in overtrained rats. Data for rats trained on a 50 -s peak-interval $(\mathrm{PI})$ timing procedure. Mean difference (mean \pm SEM) in peak time (s) between the paired control (CON) and methamphetamine (MAP) treatments for rats receiving either the 0.5 or $1.0 \mathrm{mg} / \mathrm{kg}$ dose of MAP. Difference measures are plotted as a function of minimal (blue), intermediate (green), or extended (purple) amounts of training in the 50-s PI procedure. Adapted from Cheng et al (2007b).

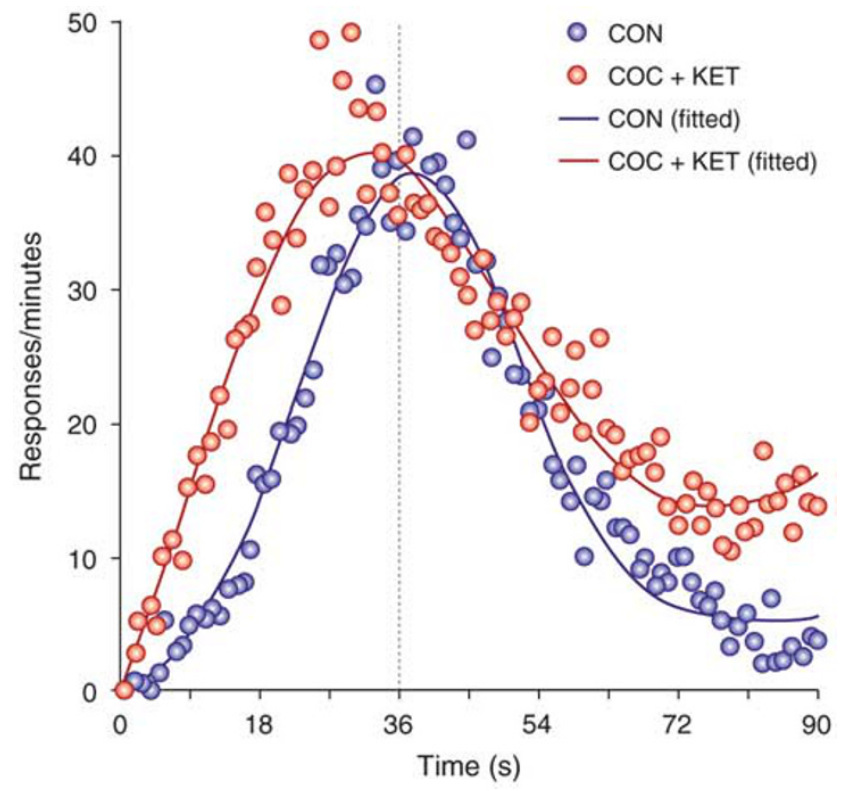

Figure 8. Ketamine 'unlocks' habit formation. Data for rats trained on a 36-s peak-interval (PI) timing procedure. Mean response rate (responses per min) is plotted as a function of signal duration for 7-month-old rats given an extended level of training ( $\geqslant 180$ sessions) on a 36-s PI procedure. Blue circles indicate performance after control (CON) saline injections and red circles indicate performance after cocaine + ketamine $(\mathrm{COC}+\mathrm{KET}-15+10 \mathrm{mg} / \mathrm{kg})$ cocktail injections. Solid lines represent the curve-fitting results of the two conditions (blue for $\mathrm{CON}$ and red for $\mathrm{COC}$ + KET). Adapted from Cheng et al (2007a).
2006; Kalivas, 2009; Williamson et al, 2008). In summary, the full spectrum of striatal interactions with other brain regions likely involves dopaminergic signals from the midbrain that is more related to clock speed and the 'clock pattern,' cholinergic signals that are more directly related to memory storage and the 'memory pattern,' and glutamatergic signals from cortical regions and the thalamus that are possibly more related to habit formation (see Pennartz et al, 2009; Wang et al, 2006).

\section{NEUROPHYSIOLOGICAL MECHANISMS OF TIMING}

\section{Ensemble Neural Response for Interval Timing}

Findings from numerous studies on the neuroanatomical substrates of interval timing suggest that nigrostriatal DA pathways and corticostriatal circuits are engaged by timing behavior. Within these circuits, the dorsal striatum seems to have a central role in timing because it provides a converging area for both midbrain DA and cortical glutamatergic inputs. If interval timing critically relies on the dorsal striatum, as suggested by the animal lesion studies and human fMRI experiments described above, one would expect that neural activity in the dorsal striatum reflects the dynamic changes observed in timing when subjects are performing interval-timing tasks. Indeed, electrophysiological recordings from the dorsal striatum have revealed that ensembles of striatal neurons show neural firing rates that increase around the expected time of reward and decrease once the expected time of reward has passed (Matell et al, 2003). This finding substantiates the development of the striatal-beat frequency (SBF) model for interval timing, which highlights the input-output relationship between the dorsal striatum and other brain regions. In essence, the SBF model states that striatal neurons receive numerous cortical inputs, and then integrate and fire action potentials if the input signals pass a predetermined threshold or reach a specific ensemble firing pattern (Matell and Meck, 2004). Once the neural computation is complete, the dorsal striatum sends a signal to other BG regions, and the $B G$, in turn, send signals back to the frontal cortex (eg, motor cortex) through the thalamus.

The role of dopamine for interval timing within the framework of SBF is supported by findings that midbrain dopamine neurons are very sensitive to the durations being timed at trial onset and to the expected time of reward (Fiorillo et al, 2003, 2008), both presumably providing 'timestamps' in the neural circuits. Without proper 'timestamps,' provided by dopamine signals in the circuits, behaviors may lose temporal regulation as evidenced by lesion studies (Buhusi and Meck, 2005; Meck, 2006a,b). This cortico-striato-thalamo-cortical loop may be critical for interval timing, temporal integration (Dale et al, 2010), motor planning (Mita et al, 2009), as well as working memory (Harrington et al, 2010; Lustig et al, 2005). Indeed, as mentioned above, a recent electrophysiological recording 
study observed that neurons in the pre-SMA and SMA in monkeys show firing patterns that are selective to different durations, with the degree of activity evolving as a function of the duration being timed (Mita et al, 2009). These data are consistent with the human fMRI data reviewed above, suggesting a key role for SMA in the explicit estimation of a stimulus duration that is currently unfolding in time. Another recent study has shown that neurons in the prefrontal cortex and the striatum of macaque monkeys encode temporal information (between 150 and $500 \mathrm{~ms}$ ) when monkeys were performing a routine visuomotor task, that is, explicit timing was not required (Jin et al, 2009). Yet, other electrophysiological studies of implicit timing (the hazard function) in monkeys have suggested a more context-dependent representation of implicit timing in a variety of cortical areas. For example, neural activity was shown to vary dynamically as a function of elapsing time and the likelihood of target onset in early visual cortex in a visual discrimination task (Ghose and Maunsell, 2002), in primary motor cortex in a pointing task (Riehle et al, 1997), and in parietal cortex in a spatial saccade task (Janssen and Shadlen, 2005). Whether striatal or SMA neurons also fired simultaneously with neurons in each of these areas, across different task contexts, is of course unknown (though see Bueti et al, (2010) for recent fMRI evidence that frontal activity also follows the hazard function). It is important to note, however, that the timing of cortical activity, in the motor cortex at least, seems to reflect the scalar property of interval timing (Gibbon et al, 1984), thereby showing timescale invariance, that is, 'time is like a rubberband' (Renoult et al, 2006).

At the cellular level, each striatal MSN receives approximately 10 000-30 000 cortical inputs (Wilson, 1995), rendering the MSN an ideal place in which to converge cortical signals for further information processing. Individual MSNs show a bi-modal distribution of its resting membrane potential, or the so-called 'Up state' and 'Down state,' determined by how close the resting membrane potential is to the threshold potential (Calabresi et al, 1990). During the 'Down state,' each MSN shows a more negative resting membrane potential due to intrinsic channel properties on the membrane and perhaps because of local inhibition from nearby interneurons (discussed below). This negativity makes it difficult for MSNs to fire action potentials because a higher voltage change is required to reach the threshold potential. In contrast, when the MSNs are in the 'Up state,' it is easier for them to fire action potentials because their resting membrane potential is now closer to the threshold potential. Hence, factors that determine the 'Up state' and the 'Down state' of the MSNs will also determine the output probability of the MSNs, which, in turn, will determine their contribution to interval timing and other motor functions.

\section{Interneurons in the Striatum}

Although MSNs are the principal neurons in the dorsal striatum, the importance of interneurons in the dorsal striatum should not be overlooked as they have an important role in regulating the firing probabilities of MSNs. Among these interneurons, three major types of interneuron have received attention according to their electrophysiological properties and the neurotransmitters they release (as recently reviewed by Kreitzer, 2009). Interneurons that show tonic activity are referred to as tonically active neurons (TANs) and release ACh when they fire action potentials. Other interneurons that release GABA can be further classified into fast-spiking interneurons (FSIs) and low-threshold spiking (LTS) interneurons. Together, these interneurons 'sculpt' the firing probability of the MSNs in the striatum, perhaps by modifying their 'Up' and 'Down' states, thereby dictating information processing in the dorsal striatum.

Cholinergic interneurons (TANs) are larger in size than all other types of neuron in the striatum, a feature that allows us to easily identify them among other neurons (Izzo and Bolam, 1988). Another feature of TANs is the aspiny structures on their dendrites, implying a lack of point-to-point communication between them and upstream neurons. Hence, these TANs are thought to function similarly to a sensor that monitors the concentration gradient of the neurotransmitters that they respond to. In in vivo studies, TANs respond to salient signals by showing a brief decrease in neural firing rate upon the onset of a reward or salient stimulus, compared with a brief increase in the neural firing rate of DA neurons to the same event (Apicella et al, 2007; Apicella, 2007; Morris et al, 2004). This distinct activity pattern of TANs can be observed in the case of natural rewards, or a salient stimulus that reliably predicts a natural reward, in rodents (Reynolds and Wickens, 2004) and primates (Aosaki et al, 1995). Together with the increased activity of midbrain DA neurons given a reward or salient stimulus, one can infer that the TANs and DA neural terminals are cooperating with one another in the striatum, although they show differential effects in terms of firing rate when presented with the delivery or omission of an expected reward (Apicella et al, 2009). Exactly how the coordination between MSNs and TANs within striatal circuits regulates the clock, memory, and decision processes involved in interval timing is an important question that remains to be addressed (Kubota et al, 2009).

Although the neurophysiological properties of both FSI and LTS are quite similar (high baseline firing rate and GABA releasing), one can still distinguish between them by the type of receptors that are expressed on their dendrites. Although both FSI and LTS have DA D5 receptors expressed on their cell body (Centonze et al, 2003), nicotinic cholinergic receptors (nAChRs, see Zhou et al, 2002) are expressed only on FSI. The fact that nAChRs are only expressed on FSI in the striatum makes FSI unique because this makes the FSI a fast responder to the cholinergic inputs provided by nearby TANs. When TANs are releasing ACh onto the FSIs, the FSIs will be excited and thus keep inhibiting their targeting MSNs. Thus, TANs can also control MSNs by their direct influence (ie, nAChRs) on FSI. 
How this TAN-FSI-MSN circuit may contribute to interval timing is discussed below.

\section{The Role of TAN-FSI-MSN Circuits in Timing}

In the field of interval timing, one remarkable phenomenon is that the accuracy and precision of timing can be shown to be independent of one another (Buhusi and Meck, 2005). The TAN-FSI-MSN local circuits may contribute to the precision of timing in the following way. Because the TANs are constantly sending excitatory ACh signals to the FSI that inhibits the MSNs, when the MSNs receive inhibitory signals from the FSI, they are prohibited from sending output signals to the downstream motor pathways. Thus, TANs may also have a role in timing the initiation, or withholding, of movement (Lee et al, 2006). This tonic inhibition is maintained until the midbrain DA signal arrives at the TANs because a salient signal or rewarding signal briefly inhibits the TANs (Morris et al, 2004), thus removing the tonic inhibition from the FSI to the MSNs. As such, one can readily imagine that if the ACh signal from the TANs to the FSI is enhanced, the inhibition from FSI to the MSNs will also be enhanced. This will make it more difficult for the MSNs to transmit output signals, which in turn, may increase the signal-to-noise ratio in the timing circuits such that a stronger input signal would be required to activate MSNs. It has been shown that rats treated with choline, a precursor of $\mathrm{ACh}$, show sharper timing functions (ie, greater precision) compared with control rats (Cheng and Meck, 2007). In other words, the accuracy of timing between the choline-supplemented and control rats is the same, but the precision of timing in the cholinesupplemented rats is superior to the controls - suggesting that choline-induced upregulation of $\mathrm{ACh}$ release in the striatum is probably responsible for this effect (Cheng et al, 2008; Meck, 2007). A larger 'quantal' release of ACh by the TANs enables a stronger tonic inhibition from the FSI to the MSNs, thus a better signal-to-noise ratio is available in the TAN-FSI-MSN circuits for interval timing.

\section{CLINICAL IMPLICATIONS}

There is a striking neuroanatomical overlap between the areas consistently recruited by timing tasks and those traditionally implicated in the processes of motor selection and preparation (eg, BG and SMA). These two processes also overlap from a neurochemical point of view, with the dopaminergic D2 receptor system being implicated in both timing and motor function. Such neural overlap has provided therapeutic benefits for patients suffering from motor disorders: by providing external timing information, such as rhythmic auditory tones, some of the motor symptoms of PD can be alleviated (Thaut et al, 1996; Lim et al, 2005) perhaps through stimulation of shared neural substrates.

However, the deleterious effects of D2 antagonists on timing performance means that patient groups being treated with dopaminergic drugs acting on this receptor system (eg, neuroleptics in schizophrenia) are likely to show dysfunctional timing behavior as a result of the medication (Goldstone et al, 1979). Conversely, DA-enhancing drugs in other psychiatric (eg, methylphenidate in ADHD) or neurological (eg, L-DOPA in PD) disorders can inadvertently improve timing (Koch et al, 2009; Rubia et al, 2009) as a beneficial side effect of their principal action on, for example, motor dysfunction or impulse control. In fact, impulsivity has recently been recast as being primarily a disorder of timing dysfunction (Rubia et al, 2009; Wittmann and Paulus, 2008), meaning that any therapeutic strategies for improving timing would consequently improve behavioral signs of impulsivity. Functional neuroimaging evidence shows that neuroleptics (Agid et al, 2007; Dodds et al, 2009), methylphenidate (Shafritz et al, 2004; Clatworthy et al, 2009), and L-DOPA (Kelly et al, 2009; Kraft et al, 2009) modulate striatal function and connectivity within corticostriatal networks, suggesting possible sites of action for their effects on timing function.

\section{FUTURE RESEARCH DIRECTIONS}

From a neuroanatomical point of view, one of the main goals of future research is to establish whether time is represented in a context-dependent manner in sensoryspecific processing areas or in a more context-independent manner in a dedicated region (or network of regions) that act as an internal timer. It is most likely that both mechanisms are in operation, with perhaps a switch from one to the other as the duration to be timed increases (Lewis and Miall, 2003b; Ivry and Schlerf, 2008). Another goal for future research is to investigate the possibility of functional specialization within key timing areas, such as BG or SMA, based on the sensorimotor characteristics of the timing task (eg, sub/suprasecond durations; auditory/visual markers; and perceptual/motor judgment). As such, it would be informative to try and dissociate the perceptual/motor nature of the timing task from the visual/auditory features of the sensory duration to be timed. Whether by coincidence or design, motor timing tasks have tended to use auditory stimuli (see, eg, Rao et al, 1997; Jantzen et al, 2004; Jahanshahi et al, 2006) whereas perceptual timing tasks have more often used visual stimuli (see, eg, Ferrandez et al, 2003; Lewis and Miall, 2003a; Coull et al, 2004). Of course, there are exceptions (see, eg, Bueti et al, 2008b; Rao et al, 2001; Tregellas et al, 2006) but a formal dissociation of these task characteristics might help explain some of the inconsistencies in the literature.

At the neuronal level, future studies will require a cell type-specific stimulation protocol to distinguish the functions/properties of different subtypes of neurons and/or pathways within the key timing areas. Recently, the technique of optogenetics (as reviewed by Scanziani and Hausser, 2009) provides a promising tool for achieving the goal of dissecting the functional roles of specific cell 
subtypes within a given neural circuit because of the ability to selectively activate or inactivate light sensitive ion channels in target cells (see, eg, Gradinaru et al, 2009). Optogenetic stimulation of light-sensitive channels such as channelrhodopsin-2 (ChR2) with patterned laser light of a specific wavelength can be used to transiently activate or inactivate DA function in brain regions thought to be involved in timing. For example, mice expressing CRE recombinase under control of the tyrosine hydroxylase promoter (TH-CRE) can be used to genetically target dopaminergic neurons. TH-CRE mice would then be stereotaxically injected into the targeted brain areas (eg, lateral or medial dorsal striatum) with a CRE-inducible adeno-associated virus coding for ChR2 (in the case of optical excitation) or with halorhodopsin (in the case of optical inhibition). Using these systems to specifically activate or inactivate DA neurons with high temporal precision, precise circuit-mapping experiments for various timing functions (eg, stop or reset) or properties (scalar variance or altered clock speed) can be conducted (see Church, 1984; Gibbon et al, 1997; Stuber, 2010). For example, one can further dissociate the functional roles of 'direct' and 'indirect' pathways (ie, D1 and D2 pathway) in the BG using this technique.

From a pharmacological standpoint, a key objective should be to dissociate drug effects on timing from effects on supporting task processes that themselves evolve over time, for example, working memory or sustained attention. Just because a drug affects timing only in the suprasecond and not millisecond range does not necessarily mean that it affects only working memory or attentional processes rather than interval timing per se (see, eg, Rammsayer, 1993, 1997a). If a drug modulated suprasecond timing, but did not affect performance on a control task that was carefully matched for working memory and sustained attention demands (see, eg, Coull et al, 2004), this would provide evidence for neurochemical modulation of suprasecond timing independent from mnemonic or attentional effects.

Finally, we should not forget that functional neuroimaging and psychopharmacology are mutually informative approaches in the study of timing and time perception. Pharmacological manipulation could prove useful for investigating the neuroanatomical substrates of interval timing by providing a functional neurochemical 'lesion,' which could help inform theories of dedicated $v s$ distributed timers in the brain. Reciprocally, functional neuroimaging is useful for psychopharmacological research as it allows the brain area(s) through which the drug is exerting its effects on timing to be pinpointed and identified. Anatomical localization of the neurochemical modulation of timing could be measured as attenuation or enhancement of activity in the network of areas activated by the timing, $v s$ a control, task (it is crucial to appreciate that the interaction between phamacological treatment (drug/placebo) and cognitive context (timing/control task) indexes a modulation of timing-related activity, with more direct drug effects on non-cognitive physiological factors (eg, blood flow) being factored out). By comparing patterns of timingspecific brain activity between the drug and placebo sessions, it is possible to identify which elements of the timing-related network have been modified by the drug. For example, it would be possible to determine whether haloperidol impairs timing by modulating activity in the nigrostriatal and/or mesolimbic dopaminergic pathways.

\section{ACKNOWLEDGEMENTS}

JTC is supported by the CNRS and by ECRP-SS grant 06_ECRP_FP009. WHM was supported, in part, by the National Institutes of Mental Health grant R01MH073057 and by a fellowship from the James McKeen Cattell Fund.

\section{DISCLOSURE}

The authors declare no conflict of interest.

\section{REFERENCES}

Agid O, Mamo D, Ginovart N, Vitcu I, Wilson AA, Zipursky RB et al (2007). Striatal vs extrastriatal dopamine D2 receptors in antipsychotic response-a double-blind PET study in schizophrenia. Neuropsychopharmacology 32: 1209-1215.

Akkal D, Escola L, Bioulac B, Burbaud P (2004). Time predictability modulates pre-supplementary motor area neuronal activity. NeuroReport 15: 1283-1286.

Alexander GE, DeLong MR, Strick PL (1986). Parallel organization of functionally segregated circuits linking basal ganglia and cortex. Ann Rev Neurosci 9: 357-381.

Aosaki T, Kimura M, Graybiel AM (1995). Temporal and spatial characteristics of tonically active neurons of the primate's striatum. J Neurophysio/ 73: 1234-1252.

Aparicio P, Diedrichsen J, Ivry RB (2005). Effects of focal basal ganglia lesions on timing and force control. Brain Cogn 58: 62-74.

Apicella P (2007). Leading tonically active neurons of the striatum from reward detection to context recognition. Trends Neurosci 30: 299-306.

Apicella P, Ravel S, Legallet E (2007). A possible role for tonically active neurons of the primate striatum in learning about temporal relationships among salient stimuli. In: Bezard E (ed). Recent Breakthroughs in Basal Ganglia Research. Nova Science Publishers: New York. pp 55-63.

An informative and innovative article that compares various functions of tonically active neurons (TANS) in the primate striatum ranging from reward-related learning to stimulus detection, movement control, and recognition of a specific context.

Apicella P, Deffains M, Ravel S, Legallet E (2009). Tonically active neurons in the striatum differentiate between delivery and omission of expected reward in a probabilistic task context. Eur J Neurosci 30: 515-526.

Artieda J, Pastor MA, Lacruz F, Obeso JA (1992). Temporal discrimination is abnormal in Parkinson's disease. Brain 115: 199-210.

One of the earliest demonstrations that Parkinson's disease patients show impaired perceptual timing across a range of modalities (tactile, auditory, and visual), with the degree of impairment correlating with disease severity. Impairments were reduced by L-DOPA medication.

Asgari K, Body S, Bak VK, Zhang ZQ, Rickard JF, Glennon JC et al (2006). Effects of 5-HT2A receptor stimulation on the discrimination of durations by rats. Behav Pharmacol 17: 51-59.

Asgari K, Body S, Rickard JF, Zhang Z, Fone KC, Bradshaw CM et al (2005). Effects of quipazine and $\mathrm{m}$-chlorophenylbiguanide (m-CPBG) on the discrimination of durations: evidence for the involvement of 5-HT2A but not 5-HT3 receptors. Behav Pharmacol 16: 43-51.

Assmus A, Marshall JC, Noth J, Zilles K, Fink GR (2005). Difficulty of perceptual spatiotemporal integration modulates the neural activity of left inferior parietal cortex. Neuroscience 132: 923-927.

Assmus A, Marshall JC, Ritzl A, Noth J, Zilles K, Fink GR (2003). Left inferior parietal cortex integrates time and space during collision judgments. Neuroimage 20(Suppl 1): S82-S88.

Balci F, Meck WH, Moore H, Brunner D (2009). Timing deficits in aging and neuropathology. In: Bizon JL, Wood A (eds). Animal Models of Human Cognitive Aging. Totowa, NJ: Humana Press. pp 161-201. 
Bares M, Lungu O, Liu T, Waechter T, Gomez CM, Ashe J (2007). Impaired predictive motor timing in patients with cerebellar disorders. Exp Brain Res 180: 355-365.

Bares M, Lungu OV, Husarova I, Gescheidt T (2010). Predictive motor timing performance dissociates between early diseases of the cerebellum and Parkinson's disease. Cerebellum 9: 124-135.

Following on from an earlier study by the same group, cerebellar, but not $P D$ patients, were shown to be impaired in using spatio-temporal information to accurately time motor performance in an implicit timing task.

Barnes R, Jones MR (2000). Expectancy, attention, and time. Cognit Psychol 41: 254-311.

Battelli L, Pascual-Leone A, Cavanagh P (2007). The 'when' pathway of the right parietal lobe. Trends Cogn Sci 11: 204-210.

Bengtsson SL, Ehrsson HH, Forssberg H, Ullen F (2005). Effector-independent voluntary timing: behavioural and neuroimaging evidence. Eur $J$ Neurosci 22: 3255-3265.

Beudel M, Galama S, Leenders KL, de Jong BM (2008). Time estimation in Parkinson's disease and degenerative cerebellar disease. NeuroReport 19: 1055-1058.

Beudel M, Renken R, Leenders KL, de Jong BM (2009). Cerebral representations of space and time. Neuroimage 44: 1032-1040.

Bhattacharjee $Y$ (2006). Neuroscience. A timely debate about the brain. Science 311: $596-598$.

Bo J, Block HJ, Clark JE, Bastian AJ (2008). A cerebellar deficit in sensorimotor prediction explains movement timing variability. J Neurophysiol 100: 2825-2832.

Breukelaar JWC, Dalrymple-Alford JC (1999). Effects of lesions to the cerebellar vermis and hemispheres on timing and counting in rats. Behav Neurosci 113: 78-90.

Brown SW (2006). Timing and executive function: bidirectional interference between concurrent temporal production and randomization tasks. Mem Cognit 34: 1464-1471.

Bueti D, Bahrami B, Walsh V (2008a). The sensory and association cortex in time perception. J Cogn Neurosci 20: 1054-1062.

Bueti D, Walsh V, Frith C, Rees G (2008b). Different brain circuits underlie motor and perceptual representations of temporal intervals. J Cogn Neurosci 20: 204-214.

Bueti D, Bahrami B, Walsh V, Rees G (2010). Encoding of temporal probabilities in the human brain. J Neurosci 30: 4343-4352.

Buhusi CV (2003). Dopaminergic mechanisms of interval timing and attention. In: Meck WH (ed). Functional and Neural Mechanisms of Interval Timing. CRC Press: Boca- Raton, FL. pp 317-338.

Buhusi CV, Meck WH (2002). Differential effects of methamphetamine and haloperidol on the control of an internal clock. Behav Neurosci 116: 291-297.

Buhusi CV, Meck WH (2005). What makes us tick? Functional and neural mechanisms of interval timing. Nat Rev Neurosci 6: 755-765.

Buhusi CV, Meck WH (2009a). Relative time sharing: new findings and an extension of the resource allocation model of temporal processing. Phil Trans $R$ Soc London B 364: 1875-1885.

Buhusi CV, Meck WH (2009b). Relativity theory and time perception: single or multiple clocks? PLoS ONE 4: e6268.

Calabresi P, Mercuri NB, Stefani A, Bernardi G (1990). Synaptic and intrinsic control of membrane excitability of neostriatal neurons. I. An in vivo analysis. J Neurophysiol 63: 651-662.

Callu D, Massioui NE, Dutrieux G, Brown BL (2009). Cognitive processing impairments in a supra-second temporal discrimination task in rats with cerebellar lesion. Neurobiol Learn Mem 91: 250-259.

Casini L, Ivry RB (1999). Effects of divided attention on temporal processing in patients with lesions of the cerebellum or frontal lobe. Neuropsychology 13: 10-21.

Centonze D, Grande C, Usiello A, Gubellini P, Erbs E, Martin AB et al (2003). Receptor subtypes involved in the presynaptic and postsynaptic actions of dopamine on striatal interneurons. J Neurosci 23: 6245-6254

Cheng RK, Ali YM, Meck WH (2007a). Ketamine 'unlocks' the reduced clock-speed effect of cocaine following extended training: evidence for dopamine-glutamate interactions in timing and time perception. Neurobiol Learn Mem 88: 149-159. Provides the first evidence of a dopamine-glutamate 'lock/unlock' mechanism involved in habit formation such that subjects exhibit a 'dopamine-insensitive' state after extended training in food-reinforced timing procedures. When in this 'locked' state, the typical 'clock-speed' altering effects of dopamine agonists (eg, cocaine) and antagonists (eg, haloperidol) are greatly reduced. This dopamineinsensitive state can be 'unlocked' by administering a combination of dopamine agonists (eg, cocaine) and NMDA antagonists (eg, ketamine).

Cheng RK, Hakak O, Meck WH (2007b). Habit formation and the loss of control of an internal clock: inverse relationship between the level of baseline training and the clock-speed enhancing effects of methamphetamine. Psychopharmacology 193: 351-362.

Different levels of training in a peak-interval timing procedure are used to show a 'dopamine-insensitive' state after extended training in which the typical 'clockspeed' altering effects of methamphetamine are dramatically reduced.
Cheng RK, MacDonald CJ, Meck WH (2006). Differential effects of cocaine and ketamine on time estimation: implications for neurobiological models of interval timing. Pharm Biochem Behav 85: 114-122.

Cheng RK, MacDonald CJ, Williams CL, Meck WH (2008). Prenatal choline supplementation alters the timing, emotion, and memory performance (TEMP) of adult male and female rats as indexed by differential reinforcement of low-rate schedule behavior. Learn Mem 15: 153-162.

Cheng RK, Meck WH (2007). Prenatal choline supplementation increases sensitivity to time by reducing non-scalar sources of variance in adult temporal processing. Brain Res 1186: 242-254.

Chiba A, Oshio K, Inase M (2008). Striatal neurons encoded temporal information in duration discrimination task. Exp Brain Res 186: 671-676.

Church RM (1984). Properties of the internal clock. Ann NY Acad Sci 423: 566-582.

Church RM, Meck WH, Gibbon J (1994). Application of scalar timing theory to individual trials. J Exp Psychol Anim Behav Process 20: 135-155.

Clatworthy PL, Lewis SJG, Brichard L, Hong YT, Izquierdo D, Clark L et al (2009). Dopamine release in dissociable striatal subregions predicts the different effects of oral methylphenidate on reversal learning and spatial working memory. J Neursci 29: 4690-4696.

Correa A, Lupianez J, Tudela P (2005). Attentional preparation based on temporal expectancy modulates processing at the perceptual level. Psychon Bull Rev 12: 328-334.

Coull J, Nobre A (2008). Dissociating explicit timing from temporal expectation with fMRI. Curr Opin Neurobiol 18: 137-144.

Coull JT (2009). Neural substrates of mounting temporal expectation. PLoS Biol 7: e1000166.

Coull JT, Buchel C, Friston KJ, Frith CD (1999a). Noradrenergically mediated plasticity in a human attentional neuronal network. Neuroimage 10: 705-715.

Coull JT, Frackowiak RS, Frith CD (1998). Monitoring for target objects: activation of right frontal and parietal cortices with increasing time on task. Neuropsychologia 36: 1325-1334.

Coull JT, Frith CD, Buchel C, Nobre AC (2000). Orienting attention in time: behavioural and neuroanatomical distinction between exogenous and endogenous shifts. Neuropsychologia 38: 808-819.

Unexpectedly premature targets activate extrastriate visual cortex, reflecting a bottom-up attentional capture mechanism, whereas unexpectedly delayed targets activate right frontal cortex, reflecting top-down voluntary shifts of attention in time, as would be implemented during the behavioral consequences of the hazard function.

Coull JT, Frith CD, Dolan RJ (1999b). Dissociating neuromodulatory effects of diazepam on episodic memory encoding and executive function. Psychopharmacology (Berl) 145: 213-222.

Coull JT, Middleton HC, Robbins TW, Sahakian BJ (1995a). Clonidine and diazepam have differential effects on tests of attention and learning. Psychopharmacology (Berl) 120: 322-332.

Coull JT, Middleton HC, Robbins TW, Sahakian BJ (1995b). Contrasting effects of clonidine and diazepam on tests of working memory and planning. Psychopharmacology (Berl) 120: 311-321.

Coull JT, Nazarian B, Vidal F (2008a). Timing, storage, and comparison of stimulus duration engage discrete anatomical components of a perceptual timing network. J Cogn Neurosci 20: 2185-2197.

Event-related $\mathrm{fMRI}$ was used to disentangle discrete cognitive components of a perceptual timing task. Timing of stimulus duration activated SMA, storage of duration into working memory engaged left putamen, whereas retrieval and comparison of durations recruited right superior temporal cortex.

Coull JT, Nobre AC (1998). Where and when to pay attention: the neural systems for directing attention to spatial locations and to time intervals as revealed by both PET and fMRI. J Neurosci 18: 7426-7435.

A temporal analog of the Posner spatial orienting of attention task revealed a hemispheric lateralization in left and right parietal cortex for temporal and spatial orienting, respectively, with temporal orienting additionally activating left ventral premotor cortex and lateral cerebellum.

Coull JT, Vidal F, Goulon C, Nazarian B, Craig C (2008b). Using time-to-contact information to assess potential collision modulates both visual and temporal prediction networks. Front Hum Neurosci 2: 10.

Coull JT, Vidal F, Nazarian B, Macar F (2004). Functional anatomy of the attentional modulation of time estimation. Science 303: 1506-1508.

Cui X, Stetson C, Montague PR, Eagleman DM (2009). Ready...go: amplitude of the FMRI signal encodes expectation of cue arrival time. PLoS Biol 7: e1000167.

Cunnington R, Windischberger C, Deecke L, Moser E (2002). The preparation and execution of self-initiated and externally-triggered movement: a study of event-related fMRI. Neuroimage 15: 373-385.

Curran HV (1991). Benzodiazepines, memory and mood: a review. Psychopharmacology (Berl) 105: 1-8. 
Dale CL, Findlay AM, Adcock RA, Vertinski M, Fisher M, Genevsky A et al (2010). Timing is everything: neural response dynamics during syllable processing and its relation to higher-order cognition in schizophrenia and healthy comparison subjects. Int J Psychophysiol 75: 183-193.

Danckert J, Ferber S, Pun C, Broderick C, Striemer C, Rock S et al (2007). Neglected time: impaired temporal perception of multisecond intervals in unilateral neglect. J Cogn Neurosci 19: 1706-1720.

Del Olmo MF, Cheeran B, Koch G, Rothwell JC (2007). Role of the cerebellum in externally paced rhythmic finger movements. I Neurophysiol 98: 145-152.

Dodds CM, Clark L, Dove A, Regenthal R, Baumann F, Bullmore E et al (2009). The dopamine D2 receptor antagonist sulpiride modulates striatal BOLD signal during the manipulation of information in working memory. Psychopharmacology (Berl) 207: 35-45.

Dreher JC, Koechlin E, Ali SO, Grafman J (2002). The roles of timing and task order during task switching. Neuroimage 17: 95-109.

Droit-Volet S, Meck WH (2007). How emotions colour our perception of time. Trends Cogn Sci 11: 504-513.

Eddington AS (1928). The Nature of the Physical World. Cambridge University Press: Cambridge, UK.

Elithorn A, Lawrence C (1955). Central inhibition-some refractory observations. Quart J Exp Psychol 11: 211-220.

Ferrandez AM, Hugueville L, Lehericy S, Poline JB, Marsault C, Pouthas V (2003). Basal ganglia and supplementary motor area subtend duration perception: an fMRI study. Neuroimage 19: 1532-1544.

Field DT, Wann JP (2005). Perceiving time to collision activates the sensorimotor cortex. Curr Biol 15: 453-458.

Fierro B, Palermo A, Puma A, Francolini M, Panetta ML, Daniele O et al (2007). Role of the cerebellum in time perception: a TMS study in normal subjects. J Neurol Sci 263: 107-112.

Fiorillo CD, Newsome WT, Schultz W (2008). The temporal precision of reward prediction in dopamine neurons. Nat Neurosci 11: 966-973.

Fiorillo CD, Tobler PN, Schultz W (2003). Discrete coding of reward probability and uncertainty by dopamine neurons. Science 299: 1898-1902.

Fortin C, Rousseau R (1998). Interference from short-term memory processing on encoding and reproducing brief durations. Psychol Res 61: 269-276.

Freeman JS, Cody FW, Schady W (1993). The influence of external timing cues upon the rhythm of voluntary movements in Parkinson's disease. J Neurol Neurosurg Psychiatry 56: 1078-1084.

Friedman WJ (1993). Memory for the time of past events. Psychological Bulletin 113: 44-66.

Garraux G, McKinney C, Wu T, Kansaku K, Nolte G, Hallett M (2005). Shared brain areas but not functional connections controlling movement timing and order. J Neurosci 25: 5290-5297.

Genovesio A, Tsujimoto S, Wise SP (2009). Feature- and order-based timing representations in the frontal cortex. Neuron 63: 254-266.

Ghose GM, Maunsell JHR (2002). Attentional modulation in visual cortex depends on task timing. Nature 419: 616-620.

Gibbon J, Church RM, Meck WH (1984). Scalar timing in memory. Ann NY Acad Sci 423: 52-77.

Gibbon J, Malapani C, Dale CL, Gallistel CR (1997). Toward a neurobiology of temporal cognition: advances and challenges. Curr Opin Neurobiol 7: 170-184.

Goldstone S, Nurnberg HG, Lhamon WT (1979). Effects of trifluoperazine, chlorpromazine, and haloperidol upon temporal information processing by schizophrenic patients. Psychopharmacology (Berl) 65: 119-124.

Gooch CM, Wiener M, Portugal GS, Matell MS (2007). Evidence for separate neural mechanisms for the timing of discrete and sustained responses. Brain Res 1156: 139-151.

Gooch CM, Wiener M, Wencil EB, Coslett HB (2010). Interval timing disruptions in subjects with cerebellar lesions. Neuropsychologia 48: 1022-1031.

Gradinaru V, Mogri M, Thompson KR, Henderson JM, Deisseroth K (2009). Optical deconstruction of parkinsonian neural circuitry. Science 324: 354-359.

Grahn JA, Brett M (2007). Rhythm and beat perception in motor areas of the brain. $J$ Cogn Neurosci 19: 893-906.

Grahn JA, McAuley JD (2009). Neural bases of individual difference in beat perception. Neuroimage 47: 1894-1903.

Halsband U, Ito N, Tanji J, Freund HJ (1993). The role of premotor cortex and the supplementary motor area in the temporal control of movement in man. Brain 116: 243-266.

Harrington DL, Boyd LA, Mayer AR, Sheltraw DM, Lee RR, Huang M et al (2004a). Neural representation of interval encoding and decision making. Cogn Brain Res 21: 193-205.

Harrington DL, Haaland KY, Hermanowicz N (1998). Temporal processing in the basal ganglia. Neuropsychology 12: 3-12.
Parkinson's disease patients were impaired on tests of both motor and perceptual timing, due to increases in clock, not motor, variability.

Harrington DL, Lee RR, Boyd LA, Rapcsak SZ, Knight RT (2004b). Does the representation of time depend on the cerebellum? Effect of cerebellar stroke. Brain 127(Part 3): 561-574.

Harrington DL, Zimbelman JL, Hinton SC, Rao SM (2010). Neural modulation of temporal encoding, maintenance, and decision processes. Cereb Cortex 20: 1274-1285

Henson RN, Shallice T, Dolan RJ (1999). Right prefrontal cortex and episodic memory retrieval: a functional MRI test of the monitoring hypothesis. Brain 122(Part 7): 1367-1381.

Hinton SC, Meck WH (1997). How time flies: functional and neural mechanisms of interval timing. In: Bradshaw CM, Szabadi E (eds). Time and Behaviour: Psychological and Neurobiological Analyses. Elsevier: New York. pp 409-457.

Hinton SC, Meck WH (2004). Frontal-striatal circuitry activated by human peakinterval timing in the supra-seconds range. Cogn Brain Res 21: 171-182.

Ho MY, Velazquez-Martinez DN, Bradshaw CM, Szabadi E (2002). 5-Hydroxytryptamine and interval timing behaviour. Pharmacol Biochem Behav 71: 773-785.

Honey GD, Honey RA, O'Loughlin C, Sharar SR, Kumaran D, Suckling J et al (2005). Ketamine disrupts frontal and hippocampal contribution to encoding and retrieval of episodic memory: an fMRI study. Cereb Cortex 15: 749-759.

Honey RA, Honey GD, O'Loughlin C, Sharar SR, Kumaran D, Bullmore ET et al (2004). Acute ketamine administration alters the brain responses to executive demands in a verbal working memory task: an FMRI study. Neuropsychopharmacology 29: 1203-1214.

Ivry RB, Keele SW (1989). Timing functions of the cerebellum. J Cogn Neurosci 1: 136-152.

An early and influential comparison of patients with Parkinson's disease, cerebellar, or cortical lesions on tasks of both motor and perceptual timing. Only cerebellar patients were impaired on both tasks, despite preserved performance on a control task of auditory discrimination.

Ivry RB, Keele SW, Diener HC (1988). Dissociation of the lateral and medial cerebellum in movement timing and movement execution. Exp Brain Res 73 $167-180$

Ivry RB, Schlerf JE (2008). Dedicated and intrinsic models of time perception. Trends Cogn Sci 12: 273-280.

Ivry RB, Spencer RM (2004). The neural representation of time. Curr Opin Neurobiol 14: 225-232

Izzo PN, Bolam JP (1988). Cholinergic synaptic input to different parts of spiny striatonigral neurons in the rat. J Comp Neurol 269: 219-234.

Jahanshahi M, Brown RG, Marsden CD (1992). Simple and choice reaction time and the use of advance information for motor preparation in Parkinson's disease. Brain 115(Part 2): 539-564.

Jahanshahi M, Brown RG, Marsden CD (1993). A comparative study of simple and choice reaction time in Parkinson's, Huntington's and cerebellar disease. J Neurol Neurosurg Psychiatry 56: 1169-1177.

Jahanshahi M, Jones CR, Dirnberger G, Frith CD (2006). The substantia nigra pars compacta and temporal processing. J Neurosci 26: 12266-12273.

James W (1890). The Principles of Psychology, 2 vols. Henry Holt (Reprinted Bristol: Thoemmes Press, 1999): New York.

Jäncke L, Loose R, Lutz K, Specht K, Shah NJ (2000). Cortical activations during paced finger-tapping applying visual and auditory pacing stimuli. Cogn Brain Res 10: 51-66.

Janssen P, Shadlen MN (2005). A representation of the hazard rate of elapsed time in macaque area LIP. Nat Neurosci 8: 234-241.

Jantzen KJ, Oullier O, Marshall M, Steinberg FL, Kelso JA (2007). A parametric fMRI investigation of context effects in sensorimotor timing and coordination. Neuropsychologia 45: 673-684.

Jantzen KJ, Steinberg FL, Kelso JA (2004). Brain networks underlying human timing behavior are influenced by prior context. Proc Natl Acad Sci USA 101: 6815-6820.

Jantzen KJ, Steinberg FL, Kelso JA (2005). Functional MRI reveals the existence of modality and coordination-dependent timing networks. Neuroimage 25: 1031-1042.

Jin DZ, Fujui N, Graybiel AM (2009). Neural representation of time in cortico-basal ganglia circuits. Proc Natl Acad Sci USA 106: 19156-19161.

Johnston A, Arnold DH, Nishida S (2006). Spatially localized distortions of event time. Curr Biol 16: 472-479.

Jones CR, Rosenkranz K, Rothwell JC, Jahanshahi M (2004). The right dorsolateral prefrontal cortex is essential in time reproduction: an investigation with repetitive transcranial magnetic stimulation. Exp Brain Res 158: 366-372. 
Jurkowski AJ, Stepp E, Hackley SA (2005). Variable foreperiod deficits in Parkinson's disease: dissociation across reflexive and voluntary behaviors. Brain Cogn 58: 49-61.

Kagerer FA, Wittmann M, Szelag E, Steinbüchel N (2002). Cortical involvement in temporal reproduction: evidence for differential roles of the hemispheres. Neuropsychologia 40: 357-366.

Kalivas PW (2008). Addiction as a pathology in prefrontal cortical regulation of corticostriatal habit circuit. Neurotox Res 14: 185-189.

Kalivas PW (2009). The glutamate homeostasis hypothesis of addiction. Nat Rev Neurosci 10: 561-572.

Kapur S, Remington G (1996). Serotonin-dopamine interaction and its relevance to schizophrenia. Am J Psychiatry 153: 466-476.

Karmarkar UR, Buonomano DV (2007). Timing in the absence of clocks: encoding time in neural network states. Neuron 53: 427-438.

Kelly C, de Zubicaray G, Di Martino A, Copland DA, Reiss PT, Klein DF et al (2009). L-dopa modulates functional connectivity in striatal cognitive and motor networks: a double-blind placebo-controlled study. J Neurosci 29: 7364-7378.

Koch G, Brusa L, Caltagirone C, Oliveri M, Peppe A, Tiraboschi P et al (2004). Subthalamic deep brain stimulation improves time perception in Parkinson's disease. NeuroReport 15: 1071-1073.

Koch G, Brusa L, Oliveri M, Stanzione P, Caltagirone C (2005). Memory for time intervals is impaired in left hemi-Parkinson patients. Neuropsychologia 43: 1163-1167.

Koch G, Costa A, Brusa L, Peppe A, Gatto I, Torriero S et al (2008). Impaired reproduction of second but not millisecond time intervals in Parkinson's disease. Neuropsychologia 46: 1305-1313.

Koch G, Oliveri M, Caltagirone C (2009). Neural networks engaged in milliseconds and seconds time processing: evidence from transcranial magnetic stimulation and patients with cortical or subcortical dysfunction. Phil Trans $R$ Soc Lond B Biol Sci 364: 1907-1918.

Koch G, Oliveri M, Carlesimo GA, Caltagirone C (2002). Selective deficit of time perception in a patient with right prefrontal cortex lesion. Neurology 59: 1658-1659.

Koch G, Oliveri M, Torriero S, Salerno S, Lo Gerfo E, Caltagirone C (2007). Repetitive TMS of cerebellum interferes with millisecond time processing. Exp Brain Res 179: 291-299.

TMS over lateral cerebellum impaired temporal reproduction in the sub-second, but not the supra-second range, whereas TMS over right prefrontal cortex preferentially impaired timing in the supra-second range.

Kraft E, Loichinger W, Diepers M, Lule D, Schwarz J, Ludolph AC et al (2009). Levodopa-induced striatal activation in Parkinson's disease: a functional MRI study. Parkinsonism Relat Disord 15: 558-563.

Kreitzer AC (2009). Physiology and pharmacology of striatal neurons. Ann Rev Neurosci 32: 127-147.

Kubota Y, Liu J, Hu D, DeCoteau WE, Eden UT, Smith AC et al (2009). Stable encoding of task structure coexists with flexible coding of task events in sensorimotor striatum. J Neurophysiol 102: 2142-2160.

Lee DN (1976). A theory of visual control of braking based on information about time-to-collision. Perception 5: 437-459.

Lee $I H$, Seitz AR, Assad JA (2006). Activity of tonically active neurons in the monkey putamen during initiation and withholding of movement. J Neurophysiol 95: 2391-2403.

Lee KH, Egleston PN, Brown WH, Gregory AN, Barker AT, Woodruff PW (2007). The role of the cerebellum in subsecond time perception: evidence from repetitive transcranial magnetic stimulation. J Cogn Neurosci 19: 147-157.

Lejeune $H$ (1998). Switching or gating? The attentional challenge in cognitive models of psychological time. Behav Process 44: 127-145.

Lejeune H, Wearden JH (2006). Scalar properties in animal timing: conformity and violations. Q J Exp Psychol 59: 1875-1908.

Lewis PA, Miall RC (2003a). Brain activation patterns during measurement of sub- and supra-second intervals. Neuropsychologia 41: 1583-1592.

One of the first neuroimaging studies to control for the sustained attention and working memory components of perceptual timing using an ingeniously conceived shape discrimination control task.

Lewis PA, Miall RC (2003b). Distinct systems for automatic and cognitively controlled time measurement: evidence from neuroimaging. Curr Opin Neurobiol 13: 250-255.

Lewis PA, Miall RC (2006). Remembering the time: a continuous clock. Trends Cogn Sci 10: 401-406

Lewis PA, Wing AM, Pope PA, Praamstra P, Miall RC (2004). Brain activity correlates differentially with increasing temporal complexity of rhythms during initialisation, synchronisation, and continuation phases of paced finger tapping. Neuropsychologia 42: 1301-1312.

Lim I, van Wegen E, de Goede C, Deutekom M, Nieuwboer A, Willems A et al (2005). Effects of external rhythmical cueing on gait in patients with Parkinson's disease: a systematic review. Clin Rehabil 19: 695-713.
Livesey AC, Wall MB, Smith AT (2007). Time perception: manipulation of task difficulty dissociates clock functions from other cognitive demands. Neuropsychologia 45: 321-331.

Luce RD (1986). Response Times: Their Role in Inferring Elementary Mental Organization. Oxford University Press: New York.

Lustig C (2003). Grandfather's clock: attention and interval timing in older adults. In: Meck WH (ed). Functional and Neural Mechanisms of Interval Timing. CRC Press: Boca-Raton, FL. pp 261-293.

Lustig C, Matell MS, Meck WH (2005). Not 'just' a coincidence: frontal-striatal interactions in working memory and interval timing. Memory 13: 441-448.

Lustig C, Meck WH (2001). Paying attention to time as one gets older. Psychol Sci 12: $478-484$

Lustig C, Meck WH (2005). Chronic treatment with haloperidol induces deficits in working memory and feedback effects of interval timing. Brain Cogn 58: 9-16.

Macar F, Vidal F (2003). The CNV peak: an index of decision making and temporal memory. Psychophysiology 40: 950-954.

Macar F, Vidal F, Casini L (1999). The supplementary motor area in motor and sensory timing: evidence from slow brain potential changes. Exp $\mathrm{Br} \operatorname{Res} 125$ : 271-280.

MacDonald CJ, Meck WH (2004). Systems-level integration of interval timing and reaction time. Neurosci Biobehav Rev 28: 747-769.

MacDonald CJ, Meck WH (2005). Differential effects of clozapine and haloperidol on interval timing in the supraseconds range. Psychopharmacology 182: 232-244.

Compared the differential effects of the typical antipsychotic drug haloperidol and the atypical antipsychotic drug clozapine on interval timing using the tri-peak procedure with 10, 30, and 90-s target durations.

MacDonald CJ, Meck WH (2006). Interaction of raclopride and preparatory-interval effects on simple reaction-time performance. Behav Brain Res 175: 62-74.

Malapani C, Deweer B, Gibbon J (2002). Separating storage from retrieval dysfunction of temporal memory in Parkinson's disease. J Cogn Neurosci 14: 311-322.

Malapani C, Dubois B, Rancurel G, Gibbon J (1998a). Cerebellar dysfunctions of temporal processing in the seconds range in humans. NeuroReport 9: 3907.

Malapani C, Rakitin B, Levy R, Meck WH, Deweer B, Dubois B et al (1998b). Coupled temporal memories in Parkinson's disease: a dopamine-related dysfunction. J Cogn Neurosci 10: 316-331.

Mangels JA, Ivry RB, Shimizu N (1998). Dissociable contributions of the prefrontal and neocerebellar cortex to time perception. Cogn Brain Res 7: 15-39.

Maricq AV, Church RM (1983). The differential effects of haloperidol and methamphetamine on time estimation in the rat. Psychopharmacology 79: 10-15.

Maricq AV, Roberts S, Church RM (1981). Methamphetamine and time estimation. $J$ Exp Psychol Anim Behav Process 7: 18-30.

Marshuetz C, Smith EE (2006). Working memory for order information: multiple cognitive and neural mechanisms. Neuroscience 139: 195-200.

Martin T, Houck JM, Bish JP, Kicic D, Woodruff CC, Moses SN et al (2006). MEG reveals different contributions of somatomotor cortex and cerebellum to simple reaction time after temporally structured cues. Hum Brain Mapp 27: 552-561.

Matell MS, Bateson M, Meck WH (2006). Single-trial analyses demonstrate that increases in clock speed contribute to the methamphetamine-induced horizontal shifts in peak-interval timing functions. Psychopharmacology 188: 201-212.

Matell MS, King GR, Meck WH (2004). Differential modulation of clock speed by the administration of intermittent versus continuous cocaine. Behav Neurosci 118: 150-156.

Matell MS, Meck WH (2000). Neuropsychological mechanisms of interval timing behaviour. BioEssays 22: 94-103.

Matell MS, Meck WH (2004). Cortico-striatal circuits and interval timing: coincidence detection of oscillatory processes. Cogn Brain Res 21: 139-170.

Matell MS, Meck WH, Nicolelis MA (2003). Interval timing and the encoding of signal duration by ensembles of cortical and striatal neurons. Behav Neurosci 117: 760-773.

Meck WH (1983). Selective adjustment of the speed of internal clock and memory processes. J Exp Psychol Anim Behav Process 9: 171-201.

Meck WH (1986). Affinity for the dopamine D2 receptor predicts neuroleptic potency in decreasing the speed of an internal clock. Pharmacol Biochem Behav 25: 1185-1189.

Meck WH (1996). Neuropharmacology of timing and time perception. Cogn Brain Res 3: 227-242.

Meck WH (2002a). Choline uptake in the frontal cortex is proportional to the absolute error of a temporal memory translation constant in mature and aged rats. Learn Motiv 33: 88-104.

Meck WH (2002b). Distortions in the content of temporal memory: neurobiological correlates. In Fountain SB, Bunsey MD, Danks JH, McBeath MK (eds). Animal 
Cognition and Sequential Behavior: Behavioral, Biological, and Computational Perspectives. Kluwer Academic Press: Boston, MA. pp 175-200.

Meck WH (2005). Neuropsychology of timing and time perception. Brain Cogn 58: 1-8.

Meck WH (2006a). Frontal cortex lesions eliminate the clock speed effect of dopaminergic drugs on interval timing. Brain Res 1108: 157-167.

Meck WH (2006b). Neuroanatomical localization of an internal clock: a functional link between mesolimbic, nigrostriatal, and mesocortical dopaminergic systems. Brain Res 1109: 93-107.

A key empirical study that distinguishes the three major dopamine pathways and their contributions to interval timing.

Meck WH (2006c). Temporal memory in mature and aged rats is sensitive to choline acetyltransferase inhibition. Brain Res 1108: 168-175.

Meck WH (2007). Acute ethanol potentiates the clock-speed enhancing effects of nicotine on timing and temporal memory. Alcohol Clin Exp Res 31: 2106-2113.

Meck WH, Church RM (1987). Cholinergic modulation of the content of temporal memory. Behav Neurosci 101: 457-464.

Meck WH, Church RM, Wenk GL, Olton DS (1987). Nucleus basalis magnocellularis and medial septal area lesions differentially impair temporal memory. $J$ Neurosci 7: 3505-3511.

Meck WH, MacDonald CJ (2007). Amygdala inactivation reverses fear's ability to impair divided attention and make time still. Behav Neurosci 121: 707-720.

Meck WH, Penney TB, Pouthas V (2008). Cortico-striatal representation of time in animals and humans. Curr Opin Neurobiol 18: 145-152.

Merchant H, Luciana M, Hooper C, Majestic S, Tuite P (2008). Interval timing and Parkinson's disease: heterogeneity in temporal performance. Exp Brain Res 184: 233-248.

Mesulam MM, Mufson EJ, Wainer BH, Levey Al (1983). Central cholinergic pathways in the rat: an overview based on alternative nomenclature. Neuroscience 10: 1185-1201.

Meyer-Lindenberg A, Rammsayer T, Ulferts J, Gallhofer B (1997). The effects of sulpiride on psychomotor performance and subjective tolerance. Eur Neuropsychopharmacol 7: 219-223.

Michon JA (1985). The complete time experience. In: Michon JA, Jackson JL (eds). Time, Mind, and Behavior. Springer: Berlin. pp 21-52.

Mita A, Mushiake H, Shima K, Matsuzaka Y, Tanji J (2009). Interval time coding by neurons in the presupplementary and supplementary motor areas. Nat Neurosci 12: $502-507$.

Moore JW, Schneider SA, Schwingenschuh P, Moretto G, Bhatia KP, Haggard P (2010). Dopaminergic medication boost action-effect binding in Parkinson's disease. Neuropsychologia 48: 1125-1132.

Morgan CJ, Curran HV (2006). Acute and chronic effects of ketamine upon human memory: a review. Psychopharmacology (Berl) 188: 408-424.

Morillon B, Kell CA, Giraud AL (2009). Three stages and four neural systems in time estimation. J Neurosci 29: 14803-14811.

Morris G, Arkadir D, Nevet A, Vaadia E, Bergman H (2004). Coincident but distinct messages of midbrain dopamine and striatal tonically active neurons. Neuron 43 : 133-143.

Morrone MC, Ross J, Burr D (2005). Saccadic eye movements cause compression of time as well as space. Nat Neurosci 8: 950-954.

Nadal R (2001). Pharmacology of the atypical antipsychotic remoxipride, a dopamine D2 receptor antagonist. CNS Drug Rev 7: 265-282.

Nakano K, Kayahara T, Tsutsumi T, Ushiro H (2000). Neural circuits and functional organization of the striatum. J Neurol 247(Suppl 5): V1-V15.

Nenadic I, Gaser C, Volz HP, Rammsayer T, Hager F, Sauer H (2003). Processing of temporal information and the basal ganglia: new evidence from fMRI. Exp Brain Res 148: 238-246.

Nichelli P, Alway D, Grafman J (1996). Perceptual timing in cerebellar degeneration. Neuropsychologia 34: 863-871.

Niemi P, Näätänen R (1981). Foreperiod and simple reaction time. Psychol Bull 89: 133-162.

O'Boyle DJ, Freeman JS, Cody FW (1996). The accuracy and precision of timing of self-paced, repetitive movements in subjects with Parkinson's disease. Brain 119: $51-70$.

O'Reilly JX, Mesulam MM, Nobre AC (2008). The cerebellum predicts the timing of perceptual events. J Neurosci 28: 2252-2260.

An fMRI study showing that the cerebellum is selectively involved in using spatio-temporal predictions to make perceptual judgments.

Ondracek JM, Dec A, Hoque KE, Lim SA, Rasouli G, Indorkar RP et al (2008). Feed-forward excitation of striatal neuron activity by frontal cortical activation of nitric signaling in vivo. Eur J Neurosci 27: 1739-1754.

Owen AM, Herrod NJ, Menon DK, Clark JC, Downey SP, Carpenter TA et al (1999). Redefining the functional organization of working memory processes within human lateral prefrontal cortex. Eur J Neurosci 11: 567-574.

Pastor MA, Artieda J, Jahanshahi M, Obeso JA (1992). Time estimation and reproduction is abnormal in Parkinson's disease. Brain 115: 211-225.
Paule MG, Meck WH, McMillan DE, McClure GYH, Bateson M, Popke EJ et al (1999). The use of timing behaviors in animals and humans to detect drug and/or toxicant effects. Neurotoxicol Teratol 21: 491-502.

Penhune VB, Zattore RJ, Evans AC (1998). Cerebellar contributions to motor timing: a PET study of auditory and visual rhythm reproduction. $J$ Cogn Neurosci 10: 752-765.

Pennartz CMA, Berke JD, Graybiel AM, Ito R, Lansink CS, van der Meer M et al (2009). Corticostriatal interactions during learning, memory processing, and decision making. J Neurosci 29: 12831-12838.

Penney TB, Gibbon J, Meck WH (2008). Categorical scaling of duration bisection in pigeons (Columba livia), mice (Mus musculus), and humans (homo sapiens). Psychol Sci 19: 1103-1109.

Penney TB, Holder MD, Meck WH (1996). Clonidine-induced antagonism of norepinephrine modulates the attentional processes involved in peak-interval timing. Exp Clin Psychopharmacol 4: 82-92.

Petrides M (1996). Specialized systems for the processing of mnemonic information within the primate frontal cortex. Phil Trans R Soc Lond B Biol Sci 351: 1455-1461; discussion 1461-1452.

Pfeuty M, Ragot R, Pouthas $V$ (2003). When time is up: CNV time course differentiates the roles of the hemispheres in the discrimination of short tone durations. Exp Brain Res 151: 372-379.

Poldrack RA, Packard MG (2003). Competition among multiple memory systems: converging evidence from animal and human brain studies. Neuropsychologia 41: 245-251.

Pouthas V, George N, Poline JB, Pfeuty M, Vandemoorteele PF, Hugueville L et al (2005). Neural network involved in time perception: an fMRI study comparing long and short interval estimation. Hum Brain Mapp 25: 433-441.

Praamstra P, Kourtis D, Kwok HF, Oostenveld R (2006). Neurophysiology of implicit timing in serial choice reaction-time performance. $J$ Neurosci 26: 5448-5455.

Praamstra P, Pope P (2007). Slow brain potential and oscillatory EEG manifestations of impaired temporal preparation in Parkinson's disease. J Neurophysio/ 98 2848-2857.

Racagni G, Canonico PL, Ravizza L, Pani L, Amore M (2004). Consensus on the use of substituted benzamides in psychiatric patients. Neuropsychobiology 50: 134-143.

Rakitin BC, Gibbon J, Penney TB, Malapani C, Hinton SC, Meck WH (1998). Scalar expectancy theory and peak-interval timing in humans. $J$ Exp Psychol Anim Behav Process 24: 15-33.

Rammsayer T (1989a). Dopaminergic and serotoninergic influence on duration discrimination and vigilance. Pharmacopsychiatry 22(Suppl 1): 39-43.

Rammsayer T (1989b). Is there a common dopaminergic basis of time perception and reaction time? Neuropsychobiology 21: 37-42.

Rammsayer T (1992). Effects of benzodiazepine-induced sedation on temporal processing. Human Psychopharm Clin Exp 7: 311-318.

Rammsayer T (2009). Effects of pharmacologically induced dopamine-receptor stimulation on human temporal information processing. NeuroQuantology 7: 103-113.

Rammsayer TH (1993). On dopaminergic modulation of temporal information processing. Biol Psychol 36: 209-222.

Rammsayer TH (1997a). Are there dissociable roles of the mesostriatal and mesolimbocortical dopamine systems on temporal information processing in humans? Neuropsychobiology 35: 36-45.

Compared the effects of the D2 antagonists haloperidol, remoxipride, and sulpiride on perceptual timing in the milliseconds ( $\sim 50 \mathrm{~ms})$ and seconds ( $1 \mathrm{~s})$ duration range. Remoxipride impaired only seconds-range timing whereas haloperidol impaired both milliseconds and seconds-range timing, highlighting the importance of the nigrostriatal rather than mesolimbic dopamine pathways in timing.

Rammsayer TH (1997b). Effects of body core temperature and brain dopamine activity on timing processes in humans. Biol Psychol 46: 169-192.

Rammsayer TH (1999). Neuropharmacological evidence for different timing mechanisms in humans. Q J Exp Psychol B 52: 273-286.

Rammsayer TH (2006). Effects of pharmacologically induced changes in NMDA receptor activity on human timing and sensorimotor performance. Brain Res 1073-1074: 407-416.

Rammsayer TH, Hennig J, Haag A, Lange N (2001). Effects of noradrenergic activity on temporal information processing in humans. $Q J$ Exp Psychol $B$ 54: 247-258.

Rammsayer TH, Vogel WH (1992). Pharmacologic properties of the internal clock underlying time perception in humans. Neuropsychobiology 26: 71-80.

Rao SM, Harrington DL, Haaland KY, Bobholz JA, Cox RW, Binder JR (1997). Distributed neural systems underlying the timing of movements. J Neurosci 17: 5528-5535. One of the first neuroimaging studies of interval timing. The continuation phase of the paced finger tapping task preferentially activated SMA, left putamen, right prefrontal cortex, and thalamus. 
Rao SM, Mayer AR, Harrington DL (2001). The evolution of brain activation during temporal processing. Nat Neurosci 4: 317-323.

Renoult L, Roux S, Riehle A (2006). Time is a rubberband: neuronal activity in monkey motor cortex in relation to time estimation. Eur J Neurosci 23: 3098-3108.

Reutimann J, Yakovlev V, Fusi S, Senn W (2004). Climbing neuronal activity as an event-based cortical representation of time. J Neurosci 24: 3295-3303.

Reynolds JNJ, Wickens JR (2004). The corticostriatal inputs to giant aspiny interneurons in the rat: a candidate pathway for synchronizing the response to reward-related cues. Brain Res 1011: 115-128.

Riehle A, Grün S, Diesmann M, Aertsen A (1997). Spike synchronization and rate modulation differentially involved in motor cortical function. Science 278: 1950-1953.

Rubia K, Halari R, Christakou A, Taylor E (2009). Impulsiveness as a timing disturbance: neurocognitive abnormalities in attention-deficit hyperactivity disorder during temporal processes and normalization with methylphenidate. Phil Trans R Soc Lond B Biol Sci 364: 1919-1931.

Sakai K, Hikosaka O, Takino R, Miyauchi S, Nielsen M, Tamada T (2000). What and when: parallel and convergent processing in motor control. J Neurosci 20: 2691-2700.

Scanziani M, Hausser M (2009). Electrophysiology in the age of light. Nature 461: 930-939.

Schenk T, Baur B, Steude U, Botzel K (2003). Effects of deep brain stimulation on prehensile movements in PD patients are less pronounced when external timing cues are provided. Neuropsychologia 41: 783-794.

Shafritz KM, Marchione KE, Gore JC, Shaywitz SE, Shaywitz BA (2004). The effects of methylphenidate on neural systems of attention in attention deficit hyperactivity disorder. Am J Psychiatry 161: 1990-1997.

Shih LY, Kuo WJ, Yeh TC, Tzeng OJ, Hsieh JC (2009). Common neural mechanisms for explicit timing in the sub-second range. NeuroReport 20: 897-901.

Smith JG, Harper DN, Gittings D, Abernethy D (2007). The effect of Parkinson's disease on time estimation as a function of stimulus duration range and modality. Brain Cogn 64: 130-143.

Spencer RM, Ivry RB (2005). Comparison of patients with Parkinson's disease or cerebellar lesions in the production of periodic movements involving event-based or emergent timing. Brain Cogn 58: 84-93.

Spencer RM, Verstynen T, Brett M, Ivry R (2007). Cerebellar activation during discrete and not continuous timed movements: an fMRI study. Neuroimage 36: 378-387.

Spencer RM, Zelaznik HN, Diedrichsen J, Ivry RB (2003). Disrupted timing of discontinuous but not continuous movements by cerebellar lesions. Science 300: 1437-1439

St Jacques P, Rubin DC, LaBar KS, Cabeza R (2008). The short and long of it: neural correlates of temporal-order memory for autobiographical events. J Cogn Neurosci 20: 1327-1341.

Stuber GD (2010). Dissecting the neural circuitry of addiction and psychiatric disease with optogenetics. Neuropsychopharmacology 35: 341-342.

Stuss DT, Alexander MP, Shallice T, Picton TW, Binns MA, Macdonald R et al (2005). Multiple frontal systems controlling response speed. Neuropsychologia 43: 396-417.

Takahashi Y, Roesch MR, Stalnaker TA, Schoenbaum G (2007). Cocaine exposure shifts the balance of associative encoding from ventral to dorsolateral striatum. Front Integr Neurosci 1: 11

Thaut MH, Mclntosh GC, Rice RR, Miller RA, Rathbun J, Brault JM (1996). Rhythmic auditory stimulation in gait training for Parkinson's disease patients. Mov Disord 11: 193-200.

Theoret H, Haque J, Pascual-Leone A (2001). Increased variability of paced finger tapping accuracy following repetitive magnetic stimulation of the cerebellum in humans. Neurosci Lett 306: 29-32.

Tregellas JR, Davalos DB, Rojas DC (2006). Effect of task difficulty on the functional anatomy of temporal processing. Neuroimage 32: 307-315.

Treisman M (1963). Temporal discrimination and the indifference interval: implications for a model of the 'internal clock'. Psychol Monogr 77: 1-31.

Trivino M, Correa A, Arnedo M, Lupianez J (2010). Temporal orienting deficit after prefrontal damage. Brain 133(Part 4): 1173-1185.
Vallesi A, Mclntosh AR, Shallice T, Stuss DT (2009). When time shapes behavior: fMRI evidence of brain correlates of temporal monitoring. J Cog Neurosci 21: 1116-1126.

Vallesi A, Mussoni A, Mondani M, Budai R, Skrap M, Shallice T (2007a). The neural basis of temporal preparation: insights from brain tumor patients. Neuropsychologia 45: 2755-2763.

Vallesi A, Shallice T, Walsh V (2007b). Role of the prefrontal cortex in the foreperiod effect: TMS evidence for dual mechanisms in temporal preparation. Cereb Cortex 17: 466-474

TMS over right, but not left, dorsolateral prefrontal cortex reduced the benefit normally afforded by the predictive power of the flow of time ('hazard function') in a speeded RT task.

Vollenweider FX, Vollenweider-Scherpenhuyzen MF, Babler A, Vogel H, Hell D (1998). Psilocybin induces schizophrenia-like psychosis in humans via a serotonin-2 agonist action. NeuroReport 9: 3897-3902.

Vollenweider FX, Vontobel P, Hell D, Leenders KL (1999). 5-HT modulation of dopamine release in basal ganglia in psilocybin-induced psychosis in man-a PET study with $\left[{ }^{11} \mathrm{C}\right]$ raclopride. Neuropsychopharmacology 20: 424-433.

Wackermann J, Wittmann M, Hasler F, Vollenweider FX (2008). Effects of varied doses of psilocybin on time interval reproduction in human subjects. Neurosci Lett 435: 51-55.

Wang Z, Kai L, Day M, Ronesi J, Yin HH, Ding J et al (2006). Dopaminergic control of corticostriatal long-term synaptic depression in medium spiny neurons is mediated by cholinergic interneurons. Neuron 50: 443-452.

Wearden JH, Lejeune $\mathrm{H}$ (2008). Scalar properties in human timing: conformity and violations. Q J Exp Psychol 61: 569-587.

Wearden JH, Smith-Spark JH, Cousins R, Edelstyn NM, Cody FW, O'Boyle DJ (2008). Stimulus timing by people with Parkinson's disease. Brain Cogn 67: 264-279.

Wiener M, Magaro CM, Matell MS (2008). Accurate timing but increased impulsivity following excitotoxic lesions of the subthalamic nucleus. Neurosci Lett 440: $176-180$

Williamson LL, Cheng RK, Etchegaray M, Meck WH (2008). 'Speed' warps time: methamphetamine's interactive roles in drug abuse, habit formation, and the biological clocks of circadian and interval timing. Curr Drug Abuse Rev 1: 203-212.

Wilson CJ (1995). The contribution of cortical neurons to the firing pattern of striatal spiny neurons. In: Houk JC, Davis JL, Beiser DG (eds). Models of Information Processing in the Basal Ganglia. MIT Press: Cambridge. pp 29-50.

Wittmann M, Carter O, Hasler F, Cahn BR, Grimberg U, Spring P et al (2007). Effects of psilocybin on time perception and temporal control of behaviour in humans. J Psychopharmacol 21: 50-64.

Wittmann M, Paulus MP (2008). Decision making, impulsivity and time perception. Trends Cogn Sci 12: 7-12.

Wolpert DM, Miall RC, Kawato M (1998). Internal models in the cerebellum. Trends Cogn Sci 2: 338-347.

Yin $\mathrm{HH}$ (2009). The role of the murine motor cortex in action. Front Integrat Neurosci 3: $1-10$.

Yin $\mathrm{HH}$, Knowlton BJ, Balleine BW (2004). Lesions of dorsolateral striatum preserve outcome expectancy but disrupt habit formation in instrumental learning. Eur J Neurosci 19: 181-189.

Yin HH, Mulcare SP, Hilário MR, Clouse E, Holloway T, Davis Ml et al (2009). Dynamic reorganization of striatal circuits during the acquisition and consolidation of a skill. Nat Neurosci 12: 333-341.

Yin HH, Ostlund SB, Balleine BW (2008). Reward-guided learning beyond dopamine in the nucleus accumbens: the integrative functions of cortico-basal ganglia networks. Eur J Neurosci 28: 1437-1448.

Zakay D, Block RA (1996). The role of attention in time estimation processes. In: Pastor MA, Artieda J (eds). Time, Internal Clocks and Movement. Elsevier Sciences: New York. pp 143-164.

Zhou FM, Wilson CJ, Dani JA (2002). Cholinergic interneuron characteristics and nicotinic properties in the striatum. J Neurobiol 53: 590-605. 